Research Article

\title{
A Study on Cut Blasting with Large Diameter Charges in Hard Rock Roadways
}

\author{
Bing Cheng $\mathbb{D}^{1,2}$ Haibo Wang, ${ }^{1,2}$ Qi Zong $\mathbb{D}^{1,2}$ Ying Xu, ${ }^{1,2}$ MengXiang Wang, \\ Qiangqiang Zheng, ${ }^{1,2}$ and Chengjie $\mathrm{Li}^{1}$ \\ ${ }^{1}$ School of Civil Engineering and Architecture, Anhui University of Science and Technology, Huainan 232001, China \\ ${ }^{2}$ State Key Laboratory of Mining Response and Disaster Prevention and Control in Deep Coal Mine, \\ Anhui University of Science and Technology, Huainan 232001, China
}

Correspondence should be addressed to Qi Zong; qzong@aust.edu.cn

Received 30 June 2020; Revised 29 August 2020; Accepted 1 September 2020; Published 10 September 2020

Academic Editor: Fengqiang Gong

Copyright (c) 2020 Bing Cheng et al. This is an open access article distributed under the Creative Commons Attribution License, which permits unrestricted use, distribution, and reproduction in any medium, provided the original work is properly cited.

To overcome the problems of poor cutting effects in hard rock roadways, a cut blasting technique with large diameter charges was developed; that is, the cut holes employ $50 \mathrm{~mm}$ diameter blast holes and $45 \mathrm{~mm}$ diameter explosive sticks, while the other holes adopt $42 \mathrm{~mm}$ diameter blast holes and $35 \mathrm{~mm}$ diameter explosive sticks. First, the effect of charge diameter on damage range and cut cavity formation was analyzed. Next, simulation of wedge cut for different charge diameters was conducted to reveal the stress wave developments and compare the stress field intensities. Finally, field tests were conducted to verify the viability of this technique. The results indicate that large diameter charges can increase the damage range around cut holes to improve the fragmentation degree of the rock mass in the cut cavity and significantly enhance the cavity formation power to better expel the rock mass fragments. The stress wave evolution of wedge cut was visualized using numerical simulations, which confirmed that the use of large diameter charges in cut holes increases the stress field intensity in the cut cavity and hence increases the damage degree of the rock mass. In this study, the use of a large diameter charge for cut blasting increased the average footage by $0.30 \mathrm{~m}$, and the average utilization rate of blast holes increased by $12.5 \%$. Therefore, the cutting effects in hard rock roadways can be improved by using large diameter charges, which increase the blasting footage and the utilization rate of blast holes.

\section{Introduction}

Drilling and blasting is a traditional, efficient, and economical construction method, which is widely used in mining excavation engineering [1-3]. During roadway excavation, cut blasting is the key to developing an additional free face for subsequent blasting, which affects the overall blasting effect and the average effective footage $[4,5]$. Based on the spatial relationship between the cut hole and the working face, cut blasting is divided into two groups: parallel cuts and incline cuts [6]. Wedge cut is the most commonly used cutting method in incline cuts, because its significant advantage is that a large cavity volume can be achieved with few blast holes and low explosive consumption [7].

For roadway excavation, cut blasting is challenging due to the lack of a free face. Therefore, finding ways to improve cut efficiency has been the focus of research in rock roadway excavation. Several researchers have studied wedge cut blasting and have obtained significant findings, some of which are reported here. Shapiro [8] compared the blasting effects of different cutting methods and proved that wedge cut is more effective than other cutting methods used for shallow hole blasting. Dai and Du [9] theoretically analyzed the mechanism of cavity formation and proposed a design method of blasting parameters for wedge cut. Cardu and Seccatore [10] presented the statistical data of industrial trends and found that wedge cut is adopted in a wide variety of applications. Zou et al. [11] analyzed the vibration suppression of stepped-wedge cut blasting by using millisecond blasting principle and conducted field tests to compare conventional-wedge cut blasting with stepped-wedge cut blasting, and they demonstrated the superiority of the latter. 
$\mathrm{Pu}$ et al. [12] determined the factors affecting wedge cut blasting based on cement mortar model tests and calculated the gray correlation degree of these factors using gray correlation theory. Zhang and Yang [13] developed a multistep cut blasting technique and performed cavity formation analyses and field blasting tests. Then they conclude that this technique has the advantages of low resistance to cavity formation and good cutting effects. Liang et al. [14] tested laboratory models and discussed the effect of cut hole angle symmetry on cut blasting and found that a symmetrical arrangement of cut hole angles can improve the utilization rate of blasting energy. Shan et al. [15] studied the effects of cut hole space, cut hole top space, and cut hole angle on cut blasting through orthogonal model tests and thus obtained the optimal layout parameters of cut holes. Yuan et al. [16] performed a model test for wedge millisecond cut blasting, using concrete as a similar material, and discussed the blasting results from the standpoints of cut cavity volume, utilization rate of blast holes, and rock fragmentation level. Man et al. [17] compared the blasting energy distribution of different cut blasting methods according to the field test results. They found that the energy distribution of wedge cut is more uniform and mainly concentrated at high frequencies, while the energy distribution of parallel cut is more concentrated at low frequencies. Using the explicit dynamic finite element software ANSYS/LS-DYNA, Yang et al. [18] simulated the duplex wedge cut with center blast holes, and the simulation results revealed the stress field distribution in the cut cavity and the process by which cavity forms at the bottom of the cut holes. $\mathrm{Hu}$ et al. [19] used AUTOCAD and ANSYS to establish a numerical model for wedge cut blasting and applied rock damage criterion in the explicit dynamic solver LS-DYNA to simulate cut cavity extension. They also further investigated the applicability of wedge cut blasting in roadway excavation from the perspectives of temporal and spatial evolution, with multidirectional cutaway views.

At present, most coal mines use $42 \mathrm{~mm}$ diameter blast holes and $35 \mathrm{~mm}$ diameter explosive sticks for the blasting excavation of rock roadways [20]. When the hardness coefficient of the rock mass is greater than 7, it is difficult to obtain a good cut blasting effect, which results in a low utilization rate of blast holes in subsequent blasting. The rapid development of drilling equipment in recent years has led to the use of drilling jumbos, which have greatly increased drilling efficiency and reduced labor intensity, which, in turn, have resulted in an increased feasibility of using large diameter charges for cut blasting. As a result, a cut blasting technology with large diameter charges has been developed to overcome the difficulties associated with cut blasting in hard rock roadways, that is, the cut holes now adopt $50 \mathrm{~mm}$ diameter blast holes and $45 \mathrm{~mm}$ diameter explosive sticks, while the other holes still use $42 \mathrm{~mm}$ diameter blast holes and $35 \mathrm{~mm}$ diameter explosive sticks. In this paper, the effects of charge diameter on damage range and cut cavity formation are analyzed based on the relevant blasting theory. Using ANSYS/LS-DYNA, simulation of wedge cut blasting for different charge diameters was conducted to understand the stress wave formations and compare the stress field intensities. Finally, field comparison tests are performed in a hard rock roadway to verify the viability of cut blasting technique with large diameter charges.

\section{Effect of Charge Diameter on Damage Range}

Based on traditional blasting theory, the damage of the surrounding medium after charge blasting mainly depends on the dynamic action of shock waves (or stress waves) and the quasi-static pressure of the detonation gas [21]. As illustrated in Figure 1, three damage zones are formed around a blast hole after charge blasting: the crushing zone, the cracking zone, and the vibration zone $[22,23]$. In the proximity of the blast hole, the rock mass within a small range is crushed by a strong compression from a shock wave to form the crushing zone. Beyond this zone, the shock wave rapidly attenuates to form a stress wave, which promotes the development of initial cracks. The simultaneous effect of the quasi-static pressure of detonation gas results in the propagation of these cracks. Thus, the cracking zone results from both the stress wave and the quasi-static pressure of the detonation gas. Finally, the stress wave attenuates to a seismic wave, which only causes an elastic vibration of the medium in the far area rather than a direct damage to the rock mass.

For rock excavation engineering, the ranges of the crushing and cracking zones are the most important considerations in the selection of blasting parameters. Recent studies indicate that the process of cut blasting can be divided into two stages. In the first stage, the rock mass in the cut cavity is damaged by blasting loads and forms rock fragments. In the second stage, the rock fragments are thrown out from the cut cavity due to the quasi-static pressure of the detonation gas. To simplify the calculations of the ranges of the crushing and cracking zones around a cut hole, only the dynamic action of the shock wave (or stress wave) is considered, and the quasi-static pressure of detonation gas is ignored [24].

When a cylindrical charged hole is initiated, it usually radiates $\mathrm{P}$ waves and shear-vertical (SV) waves. Depending on the magnitude of the detonation velocity, P-Mach or/and SVMach waves can be formed [25]. It is observed that the dynamic process of cylindrical charge blasting is complex. However, in the current research, a two-dimensional simplified model that only considers $\mathrm{P}$ waves is usually employed to calculate the damage range of cylindrical charge.

2.1. Blasting Load. The detonation pressure is an important performance index of explosives, which determines the damage level of the rock mass. Based on the ChapmanJouguet (C-J) detonation theory, the semiempirical formula for detonation pressure is expressed as [26]

$$
P_{0}=\left(\frac{1}{1+k}\right) \rho_{0} D_{0}^{2}
$$

where $P_{0}$ is the C-J detonation pressure; $k$ is the adiabatic exponent, taken as $k=3 ; \rho_{0}$ is the explosive density; and $D_{0}$ is the detonation velocity. 


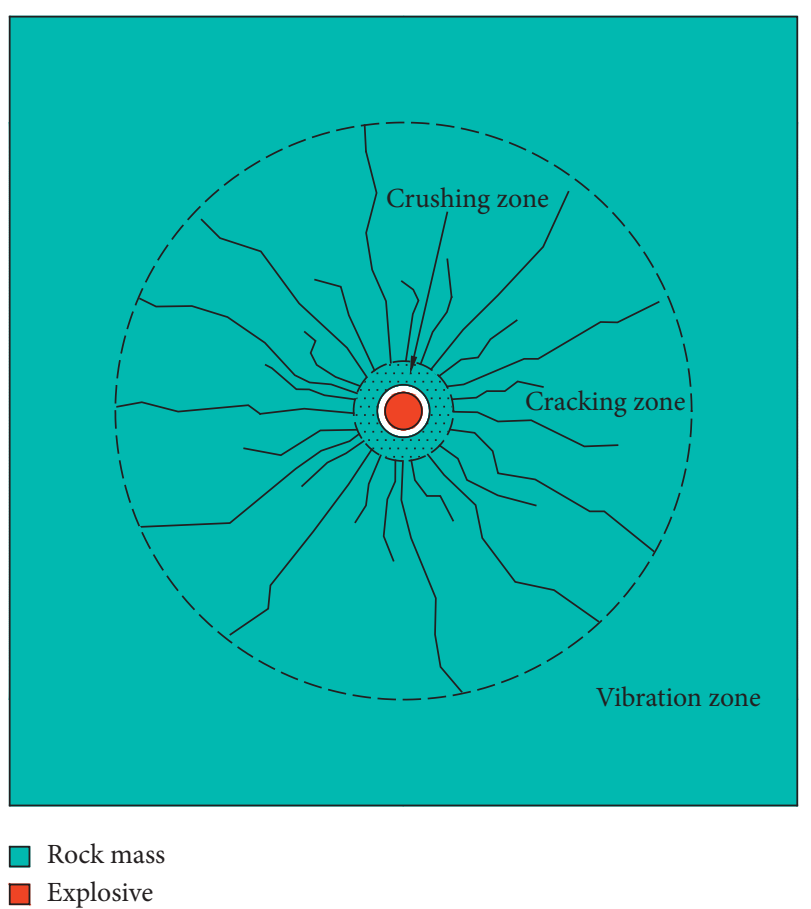

FIgURE 1: Damage zones around a blast hole.

When a radial decoupled charge structure is deployed in a blast hole, the detonation products initially compress the air gap to form the shock wave, which then acts on the blast hole wall [27]. According to the acoustic approximation theory, the initial pressure exerted on the wall of the blast hole is given by

$$
P_{r}=\left(\frac{1}{2}\right) P_{0} K^{-2 k} n,
$$

where $P_{r}$ is the initial pressure of the shock wave on the wall of the blast hole; $K$ is the radial decoupled coefficient, and $K=d_{b} / d_{c}$, with $d_{b}$ and $d_{c}$ being the diameters of the blast hole and explosive stick, respectively; and $n$ is the augmentation factor, where $n=10$.

The strong compression from the shock wave causes the formation of the crushing zone, which consumes a large amount of energy. This causes the shock wave to rapidly attenuate to a stress wave, which then spreads to the surrounding rock mass. Since the charge length is much greater than the charge diameter, this situation can be simplified to a plane strain problem, ignoring the special blasting effects at both ends of the blast hole, and the stress at a point in the rock mass can be expressed as [28]

$$
\left\{\begin{array}{l}
\sigma_{r}=P_{r} \bar{r}^{-\alpha} \\
\sigma_{\theta}=-b \sigma_{r}, \\
\sigma_{z}=\mu(1-b) \sigma_{r},
\end{array}\right.
$$

where $\sigma_{r}, \sigma_{\theta}$, and $\sigma_{z}$ are the radial stress, tangential stress, and axial stress, respectively; $\bar{r}$ is the relative distance, and $\bar{r}=r / r_{b} ; r$ is the distance between a point in the rock mass and the center of the blast hole; $r_{b}$ is the radius of the blast hole, where $r_{b}=0.5 d_{b} ; \alpha$ is the attenuation exponent, where $\alpha_{1}=2+b$ in the shock wave zone and $\alpha_{2}=2-b$ in the stress wave zone, with $b$ being the lateral pressure coefficient, and $b=\mu /(1-\mu)$; and $\mu$ is the dynamic Poisson ratio of the rock mass, where $\mu=0.8 \mu_{0}$, with $\mu_{0}$ being the static Poisson ratio.

2.2. Damage Criteria. The damage criteria are determined by the mechanical properties and real stress conditions of the rock mass. Under the blasting load, the rock mass around the blast hole is in a three-dimensional mixed stress state including compression, tension, and shear [29]. Thus, the equivalent stress of a point in the rock mass can be described as

$$
\sigma_{i}=\frac{1}{\sqrt{2}} \sqrt{\left(\sigma_{r}-\sigma_{\theta}\right)^{2}+\left(\sigma_{\theta}-\sigma_{z}\right)^{2}+\left(\sigma_{z}-\sigma_{r}\right)^{2}} .
$$

Substituting equation (3) into equation (4), we get

$$
\sigma_{i}=\frac{1}{\sqrt{2}} \sigma_{r} \sqrt{(1+b)^{2}+2 \mu(1-\mu)(1-b)^{2}+(1+b)^{2}} \text {. }
$$

Assuming $A=\sqrt{(1+b)^{2}+2 \mu(1-\mu)(1-b)^{2}+(1+b)^{2}}$, equation can be simplified as

$$
\sigma_{i}=\frac{1}{\sqrt{2}} \sigma_{r} A
$$

Based on the von Mises criterion and rock damage characteristics, the rock damage criteria can be expressed as

$$
\begin{cases}\sigma_{i}>\sigma_{\text {cd }}, & \text { (crushing zone), } \\ \sigma_{i}>\sigma_{\text {td }}, & \text { (cracking zone) }\end{cases}
$$

where $\sigma_{\mathrm{cd}}$ and $\sigma_{\mathrm{td}}$ are, respectively, the dynamic compression strength and dynamic tensile strength of rock.

In contrast to static loads, rock materials are sensitive to high strain rates that occur under blasting loads, which need to be considered in analyses involving the use of the mechanical properties of rock [30-32]. In general, the dynamic strength of rock increases with strain rate, but the sensitivity to strain rate varies for different rocks [33]. For common types of rocks, the dynamic strength varies linearly with the cube root of the strain rate [34] as follows:

$$
\left\{\begin{array}{l}
\sigma_{\mathrm{cd}}=\sigma_{c} \cdot \dot{\varepsilon}^{(1 / 3)}, \\
\sigma_{\mathrm{td}}=\sigma_{t} \cdot \dot{\varepsilon}^{(1 / 3)}
\end{array}\right.
$$

where $\sigma_{c}$ and $\sigma_{t}$ are the static compression strength and static tensile strength of rock, respectively; and $\dot{\varepsilon}$ is the strain rate, where $\dot{\varepsilon}^{(1 / 3)}=5$ in the shock wave zone and $\dot{\varepsilon}^{(1 / 3)}=3$ in the stress wave zone [24].

2.3. Blasting Damage Range. The radii of the crushing and cracking zones, after a radial decoupled cylindrical charge blasting in a blast hole, can be calculated based on the above blasting load and rock damage criteria as follows: 


$$
\begin{aligned}
& R_{c}=\left(\frac{\rho_{0} D^{2} K^{-2 k} n A}{8 \sqrt{2 \sigma_{\mathrm{cd}}}}\right)^{\left(1 / \alpha_{1}\right)} r_{b} \\
& R_{t}=\left(\frac{\rho_{0} D^{2} K^{-2 k} n A}{8 \sqrt{2} \sigma_{\mathrm{cd}}}\right)^{\left(1 / \alpha_{1}\right)}\left(\frac{\sigma_{\mathrm{cd}}}{\sigma_{\mathrm{td}}}\right)^{\left(1 / \alpha_{2}\right)} r_{b},
\end{aligned}
$$

where $R_{c}$ and $R_{t}$ are the radii of the crushing and cracking zones, respectively.

According to explosive detonation theory, the detonation velocity increases, within a certain range, with an increase in explosive stick diameter. The detonation velocities of class 2 coal mine permissible water-gel explosives with different diameters were measured by a detonation velocity meter, and the results are presented in Table 1. It is observed that the detonation velocity of a $45 \mathrm{~mm}$ diameter explosive stick is $8.4 \%$ higher than that of a $35 \mathrm{~mm}$ diameter explosive stick. Also, standardized pieces of rock roadway samples were tested for physical and mechanical properties, and the results are listed in Table 2 .

The values of the parameters for the charges, detonation velocities, and the mechanical properties of rocks noted above were substituted into equations (9) and (10) to calculate the radii of the crushing and cracking zones for different charge diameters, and the results are shown in Table 3. It can be seen that the radii of the crushing and cracking zones increase with charge diameter, and the damage range generated by a $50 \mathrm{~mm}$ diameter blast hole with a $45 \mathrm{~mm}$ diameter explosive stick is 1.31 times that generated by a $42 \mathrm{~mm}$ diameter blast hole with a $35 \mathrm{~mm}$ diameter explosive stick. Thus, further penetration of blasting cracks can be realized by large diameter charges to improve the fragmentation degree of the rock mass in the cut cavity.

\section{The Effect of Charge Diameter on Cut Cavity Formation}

3.1. Wedge Cut Blasting Model. To study the influence of charge diameter on cut cavity formation, a wedge cut blasting model was established. As illustrated in Figure 2, ACDF is the free face; AG, BH, CI, DJ, EK, and FL are the cut holes; $x$ is the cut hole top space; $y$ is the cut hole bottom space; $a$ is the cut hole space; $(H / \sin \beta)$ is the cut hole length; $\beta$ is the cut hole angle; $H$ is the vertical depth of the cut hole.

3.2. Analysis of Resistance to Cavity Formation. In addition to ACDF as a free face, five other surfaces have resistance to cavity formation. The shear resistance of AFLG, CDJI, ACIG, and FDJL can be estimated by the Mohr-Coulomb criterion, and the tensile resistance of GIJL is related to the tensile strength of the rock mass and the bottom area of the cut cavity [35].

The shear resistance of AFLG and CDJI is given by

$$
Q_{\mathrm{AFLG}}=Q_{\mathrm{CDII}}=\left(c+\sigma_{1} \tan \phi\right) \frac{(x+y) H}{2},
$$

TABLE 1: Detonation velocities of explosives with different diameters.

\begin{tabular}{lcc}
\hline$d_{c}(\mathrm{~mm})$ & $\rho_{0}\left(\mathrm{~kg} \cdot \mathrm{m}^{-3}\right)$ & $D\left(\mathrm{~m} \cdot \mathrm{s}^{-1}\right)$ \\
\hline 35 & 1100 & 3425 \\
45 & 1100 & 3713 \\
\hline
\end{tabular}

TABle 2: Physical and mechanical properties of rock mass.

\begin{tabular}{lccc}
\hline Density $\left(\mathrm{kg} \cdot \mathrm{m}^{-3}\right)$ & $\mu_{0}$ & $\sigma_{c}(\mathrm{MPa})$ & $\sigma_{t}(\mathrm{MPa})$ \\
\hline 2450 & 0.25 & 95.8 & 9.6 \\
\hline
\end{tabular}

TABLE 3: Damage ranges for different charge diameters.

\begin{tabular}{lccc}
\hline$d_{b}(\mathrm{~mm})$ & $d_{c}(\mathrm{~mm})$ & $R_{c}(\mathrm{~mm})$ & $R_{t}(\mathrm{~mm})$ \\
\hline 42 & 35 & 69 & 347 \\
50 & 45 & 91 & 453 \\
\hline
\end{tabular}

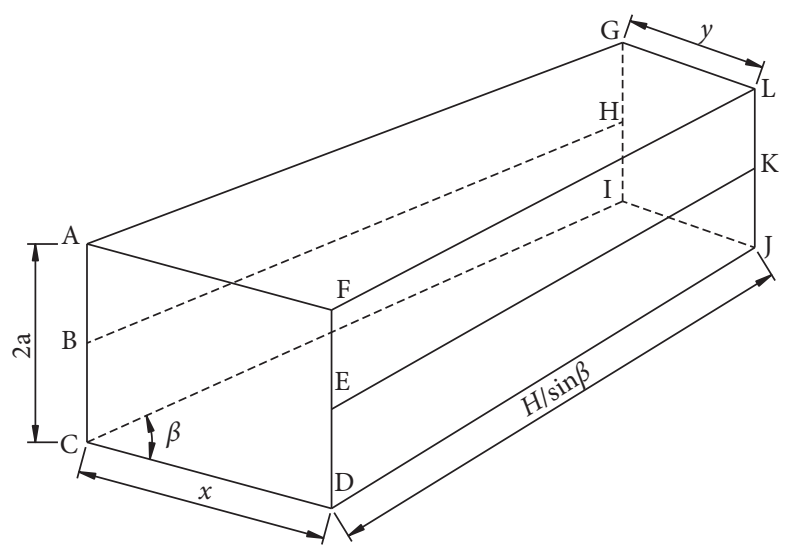

Figure 2: Wedge cut blasting model.

where $c$ is the cohesion; $\varphi$ is the internal friction angle; $\sigma_{1}$ is the vertical normal stress.

The shear resistance of ACIG and FDJL is calculated from

$$
Q_{\mathrm{ACIG}}=Q_{\mathrm{FDJL}}=\left(c+\sigma_{2} \tan \phi\right)\left(\frac{2 a H}{\sin \beta}\right),
$$

where $\sigma_{2}$ is the horizontal normal stress: $\sigma_{2}=\sigma_{1}\left(\mu_{0} / 1-\mu_{0}\right)$.

The tensile resistance $(T)$ of GIJL is expressed as

$$
T=2 a y \sigma_{t} .
$$

The cavity formation resistance $(f)$ is represented as

$$
f=Q_{\mathrm{AFLG}}+Q_{\mathrm{CDJI}}+\left(Q_{\mathrm{ACIG}}+Q_{\mathrm{FDJL}}\right) \sin \beta+T \text {. }
$$

3.3. Analysis of Cavity Formation Power. The cavity formation power is derived from the quasi-static pressure of the detonation gas. Based on adiabatic expansion theory, the force exerted directly on the rock mass, after charge blasting in cut holes with good stemming, is given by [36] 


$$
F_{0}=m P_{0} K^{-2 k} L_{c} d_{b}
$$

where $m$ is the number of cut holes; $F_{0}$ is the force from the detonating gas acting directly on the rock mass; $L_{c}$ is the charge length.

Since the force exerted directly on the rock mass is parallel to the radial direction of the cut hole and there is a certain angle between the cut hole and the free face, the component of the force towards the free face, which constitutes the cavity formation power, is described by

$$
F=F_{0} \cos \beta=m P_{0} K^{-2 k} L_{c} d_{b} \cos \beta,
$$

where $F$ is the cavity formation power.

Based on the above analysis, rock fragments can be expelled from the cut cavity when the cavity formation power is greater than the cavity formation resistance, which is expressed as

$$
F>f
$$

When the number of cut holes $(m)$, charge length $\left(L_{c}\right)$, and cut hole angle $(\beta)$ remain constant, it can be calculated that the cavity formation power generated by $50 \mathrm{~mm}$ diameter cut holes and $45 \mathrm{~mm}$ diameter explosive sticks is 2.22 times that generated by $42 \mathrm{~mm}$ diameter cut holes and $35 \mathrm{~mm}$ diameter explosive sticks. Therefore, for a constant cavity formation resistance, the cavity formation power of cut blasting with a large diameter charge is significantly greater than that of cut blasting with a small diameter charge, which is more conducive to expelling the rock mass fragments from the cut cavity.

\section{Numerical Simulation of Wedge Cut Blasting for Different Charge Diameters}

4.1. Numerical Model. To investigate the formation of the stress wave and the intensity of the stress field, three-dimensional numerical models of wedge cut blasting for two charge diameters were established by a solid element of eight nodes in ANSYS/LS-DYNA [37]. As shown in Figure 3, for both numerical models, the size of the rock mass is $4000 \mathrm{~mm} \times 3000 \mathrm{~mm} \times 3000 \mathrm{~mm}$ with six cut holes symmetrically arranged on the left and right sides of the model; the cut hole angle is $77^{\circ}$, the cut hole top space is $1500 \mathrm{~mm}$, the cut hole bottom space is $300 \mathrm{~mm}$, the cut hole space is $500 \mathrm{~mm}$, the cut hole depth is $2600 \mathrm{~mm}$, and the charge length is $1320 \mathrm{~mm}$. The difference between the two numerical models is that the model with the large diameter charge adopts $50 \mathrm{~mm}$ diameter cut holes and $45 \mathrm{~mm}$ diameter explosive sticks, while the model with the small diameter charge adopts $42 \mathrm{~mm}$ diameter cut holes and $35 \mathrm{~mm}$ diameter explosive sticks.

In this simulation, the explosive and air were defined as ALE grids, and the Lagrange algorithm was performed for the rock mass and stemming. Using the keyword * CONSTRAINED_LAGRANGE_IN_SOLID, the fluidsolid coupling algorithm was defined to realize the transfer of blasting energy from the detonation products to the rock mass and stemming [38, 39]. Nonreflecting boundaries were applied to the model surface in addition to the working face to reduce the influence of stress wave reflections on the simulation results [40,41]. Also, the keyword * INITIAL_DETONATION was used in the calculation program to define the initiation points at the bottom of each cut hole [42].

Blair $[43,44]$ noted that grid size has an important effect on calculation accuracy and time consumption. In this simulation, due to the limitation of computer capacity, small grids were used near the cut holes and at the bottom of the cut cavity to ensure precision, while large grids were adopted farther from the cut holes to reduce computational complexity and improve efficiency. Moreover, numerical convergence tests were performed to obtain a reasonable mesh. For this purpose, the number of grids was increased for successive tests until the difference between the results of two consecutive tests was less than 5\% [45]. The meshing of the rock mass model used for numerical simulations is shown in Figure 4.

4.2. Material Model. The key to conducting numerical simulations of engineering blasting is the determination of the blasting load. In this paper, the * MAT_HIGH_EXPLOSIVE_BURN model embedded in the LS-DYNA was chosen as the explosive, and the JWL state equation was used to accurately describe the relationship between the expanding volume, pressure, and energy change of detonation products [46]. The JWL state equation is expressed as [47-49]

$$
\begin{aligned}
p_{\text {eоs }}= & A_{\text {eos }}\left(1-\left(\frac{\omega}{R_{1} V}\right)\right) e^{-R_{1} V}+B_{\text {eоs }}\left(1-\left(\frac{\omega}{R_{2} V}\right)\right) e^{-R_{2} V} \\
& +\left(\frac{\omega E_{0}}{V}\right)
\end{aligned}
$$

where $p_{\text {eos }}, E_{0}$, and $V$ are the pressure, specific internal energy, and relative volume of the detonation products, respectively; and $A_{\text {eos }}, B_{\text {eos }}, R_{1}, R_{2}$, and $\omega$ are material constants. Some of the main parameters of the JWL state equation are shown in Table 4.

Air, being a fluid, is usually described by constitutive and state equations. In this simulation, the * MAT_NULL model was used as the constitutive equation, and the following linear polynomial equation was selected as the state equation $[50,51]$ :

$$
\begin{aligned}
p_{0} & =C_{0}+C_{1} \xi+C_{2} \xi^{2}+C_{3} \xi^{3}+\left(C_{4}+C_{5} \xi+C_{6} \xi^{2}\right) E_{1}, \\
\xi & =\left(\frac{\rho}{\rho_{a}}\right)-1
\end{aligned}
$$

where $p_{0}$ is the pressure, and $C_{0}, C_{1}, C_{2}, C_{3}, C_{4}, C_{5}$, and $C_{6}$ are material constants; $\xi$ is the nonlinear coefficient of viscosity; $E_{1}$ is the internal energy per unit volume; $\rho$ is the density at test conditions; $\rho_{a}$ is the nominal density. The 

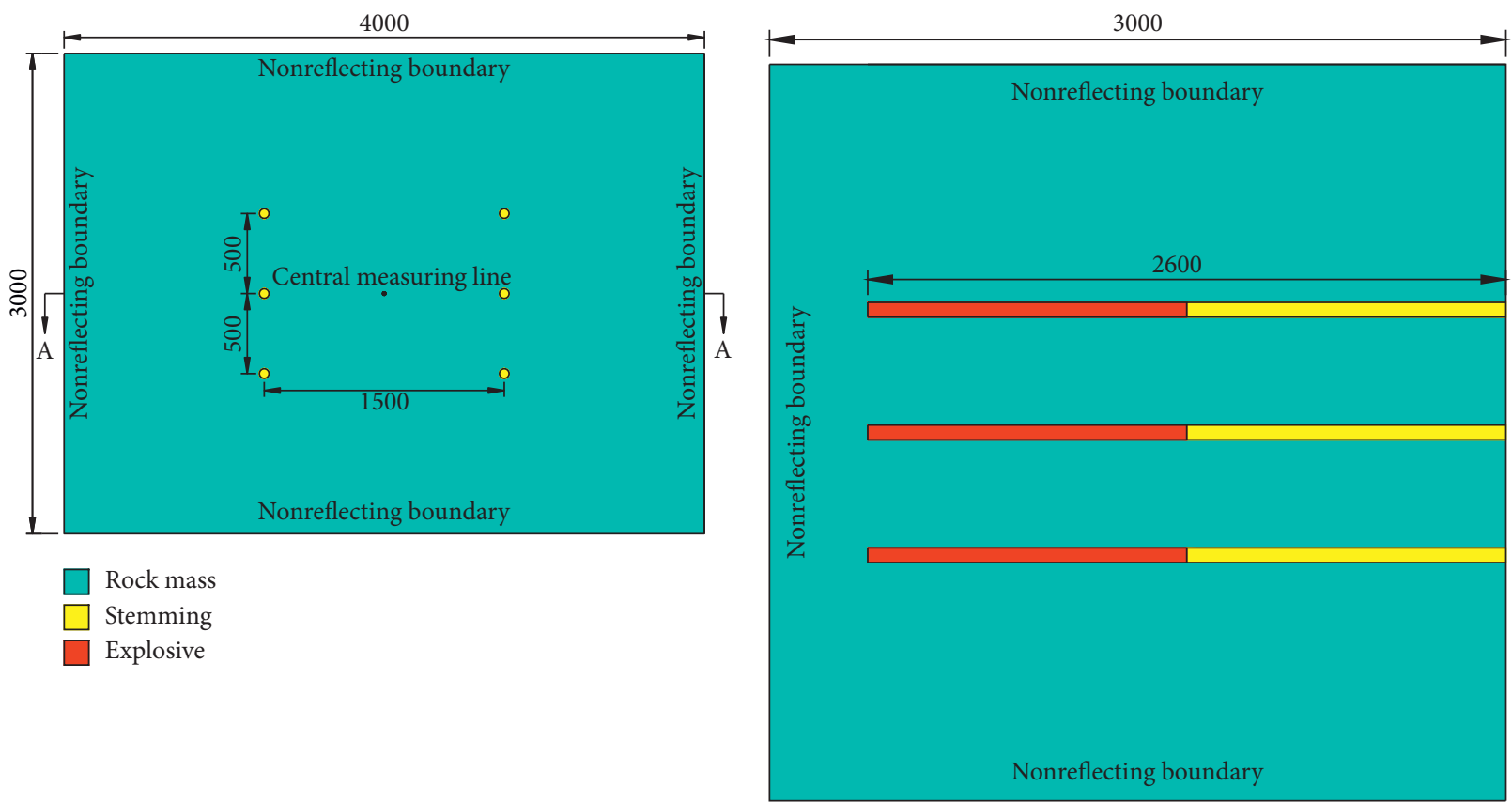

$\square$ Rock mass
$\square$ Stemming
$\square$ Explosive

(a)

(b)

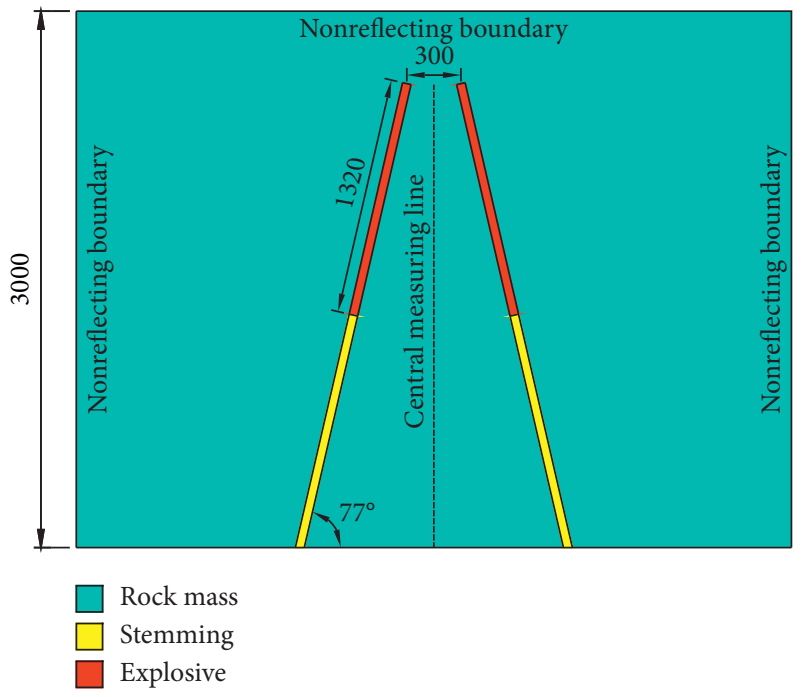

(c)

Figure 3: Numerical model of wedge cut blasting (unit: mm). (a) Front view. (b) Left view. (c) Top view (or A-A section).

parameters for air and the above linear polynomial state equations are listed in Table 5.

The rock mass was modeled using the * MAT_PLASTIC_KINEMATIC model, which considers the effect of strain under a blasting load [52]. Based on the Cowper and Symonds empirical formula, an amplification factor related to strain rate is introduced into the yield stress equation as follows [53, 54]:

$$
\begin{aligned}
\sigma_{\mathrm{Y}} & =\eta\left(\sigma_{0}+\beta_{1} E_{\mathrm{p}} \varepsilon_{\mathrm{eff}}\right), \\
\eta & =1+\left(\frac{\dot{\varepsilon}}{C}\right)^{(1 / P)},
\end{aligned}
$$

where $\sigma_{\mathrm{Y}}$ is the current yield strength; $\eta$ is the amplification factor of yield strength; $\sigma_{0}$ is the initial yield strength; $\beta_{1}$ is 


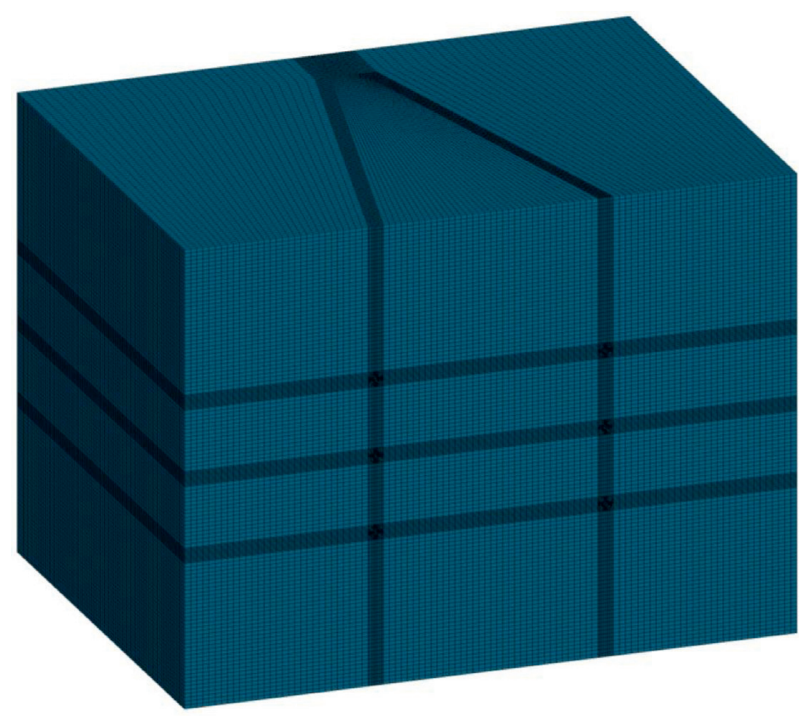

FIgURE 4: Meshing of rock mass model.

TABle 4: Parameters used in the JWL state equation for the explosive.

\begin{tabular}{lcccccc}
\hline$A_{\text {eos }}(\mathrm{GPa})$ & $B_{\text {eos }}(\mathrm{GPa})$ & $R_{1}$ & $R_{2}$ & $\omega$ & $E_{0}(\mathrm{GPa})$ & $V_{0}$ \\
\hline 214 & 0.182 & 4.15 & 0.95 & 0.15 & 4.19 & 1.0 \\
\hline
\end{tabular}

Table 5: Parameters for air and state equation.

\begin{tabular}{lccccccc}
\hline$\rho_{a}\left(\mathrm{~kg} \cdot \mathrm{m}^{-3}\right)$ & $C_{0}$ & $C_{1}$ & $C_{2}$ & $C_{3}$ & $C_{4}$ & $C_{5}$ & $C_{6}$ \\
\hline 1.25 & 0.00 & 0.00 & 0.00 & 0.00 & 0.40 & 0.40 & 0.00 \\
\hline
\end{tabular}

the hardening regulation parameter; $E_{\mathrm{p}}$ is the plastic hardening modulus; $\varepsilon_{\text {eff }}$ is the effective plastic strain; $\dot{\varepsilon}$ is the strain rate; $C$ is the Cowper strain rate parameter; $P$ is the Symonds strain rate parameter. The parameters for the rock mass material have been previously presented in Table 2 .

The stemming was modeled using the *MAT_SOIL_AND_FORM model, which can effectively simulate the liquefaction characteristics of sand under dynamic load [55]. The parameters for the stemming material are listed in Table 6.

4.3. Analysis of Simulation Results. Numerical and material models have been used to simulate the stress wave evolution of cut blasting models with small and large diameter charges; then the numerical models were segmented along A-A section in LS-PREPOST. Figures 5 and 6 show the evolution of effective stress field of the numerical models with the small and large charge diameters, respectively.

As shown in Figures 5 and 6, explosive detonation initiates at the bottom of the cut hole and propagates along the cut hole towards the free face, with the simultaneous propagation of the stress wave towards the free face with a conical wavefront. Due to the proximity of the bottoms of the cut holes, the resulting superposition of the stress waves appears in the middle of the cut cavity at $t=45 \mu \mathrm{s}$, which can enhance the damage of the rock mass in the cut cavity. With an increase in the distance between the cut holes, the superposition effect becomes weaker. Although the explosive detonation of each cut hole is completed at $t=320 \mu \mathrm{s}$, the stress wave continues to propagate towards the free face with a circular arc wavefront. When the stress wave reaches the free face at $t=490 \mu \mathrm{s}$, it is reflected as a tensile stress wave. The reflected tensile wave encounters the propagating compression wave, resulting in a complex stress superposition, which causes further damage to the rock mass in the cut cavity. The above analysis demonstrates that simulation results can reveal the stress wave evolution of wedge cut blasting.

Comparing Figures 5 and 6 , the range of high stress around the cut hole in the numerical model with the large diameter charge is significantly larger than that in the numerical model with the small diameter charge. Likewise, the stress wave superposition effect in the middle of the cut cavity in the numerical model with the large diameter charge is more significant than that in the numerical model with the small diameter charge. To compare stress field intensities in the cut cavity for different charge diameters, a measuring line extending from the free face to the bottom was placed at the center of both numerical models, as shown in Figure 3. A measuring point was placed every $0.1 \mathrm{~m}$ along this measuring line, and the peak effective stress at these measuring points was output to plot the curve of peak effective stress with cut depth.

As illustrated in Figure 7, both numerical models have the same trend in the variation of the peak effective stress with cut depth along the central measuring line. Aside from a small fluctuation at a cut depth of $1.2 \mathrm{~m}$, the peak effective stress increases with cut depth, for a cut depth in the range of $0 \sim 2.5 \mathrm{~m}$, and reaches a maximum value at a cut depth of $2.5 \mathrm{~m}$. Thereafter, the peak effective stress decreases rapidly with an increase in cut depth. It also can be seen that the peak effective stress at all measuring points of the numerical model with the large diameter charge is higher than that of the numerical model with the small diameter charge. Furthermore, the difference in peak effective stress between the two numerical models remains approximately constant for a cut depth range of $0 \sim 1.3 \mathrm{~m}$ and increases gradually for a cut depth range of $1.4 \sim 2.5 \mathrm{~m}$.

As shown in Figure 7, the maximum and average values of peak effective stress at the measuring points along the central measuring line of the numerical model with the small diameter charge are $216.8 \mathrm{MPa}$ and $86.7 \mathrm{MPa}$, respectively. The corresponding maximum and average values of peak effective stress at the measuring points of the numerical model with the large diameter charge are $318.1 \mathrm{MPa}$ and 122.7 MPa, respectively. Thus, the maximum and average values of peak effective stress at the measuring points along the central measuring line of the numerical model with the large diameter charge are $46.7 \%$ and $41.5 \%$ higher than that of the numerical model with the small diameter charge, respectively. This result demonstrates that the large diameter charge can increase the effective stress field intensity in the cut cavity and hence enhance the damage degree of the rock mass. 
TABLE 6: Parameters for the stemming material.

\begin{tabular}{lccc}
\hline Density $\left(\mathrm{kg} \cdot \mathrm{m}^{-3}\right)$ & Bulk modulus $(\mathrm{GPa})$ & Shear modulus $(\mathrm{GPa})$ & Tensile cut-off $(\mathrm{GPa})$ \\
\hline 1800 & 1.32 & 0.016 & 0.0 \\
\hline
\end{tabular}

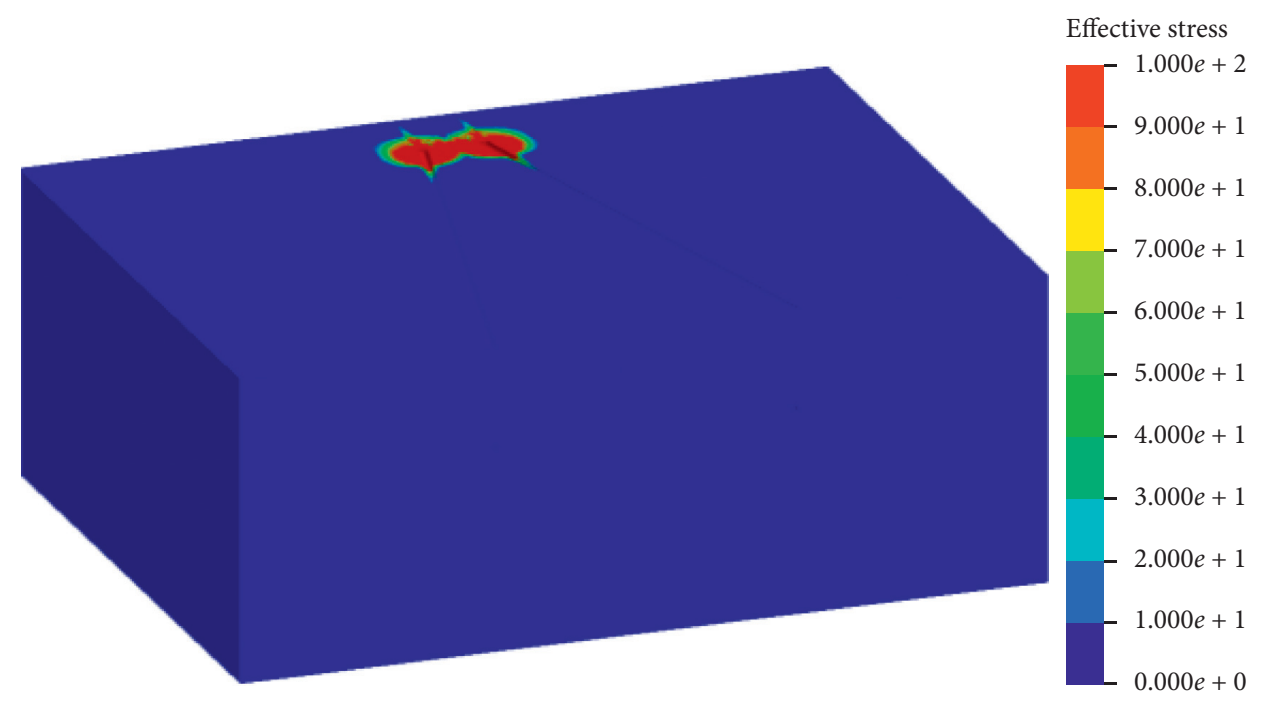

(a)

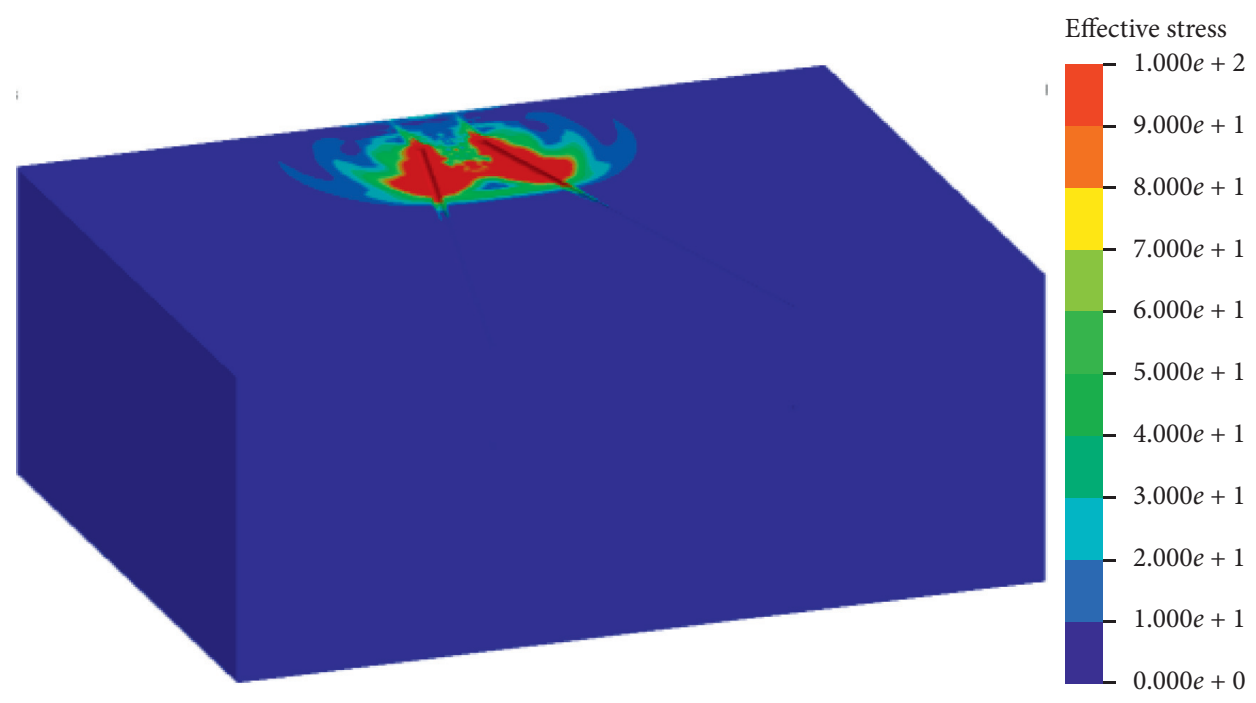

(b)

Figure 5: Continued. 


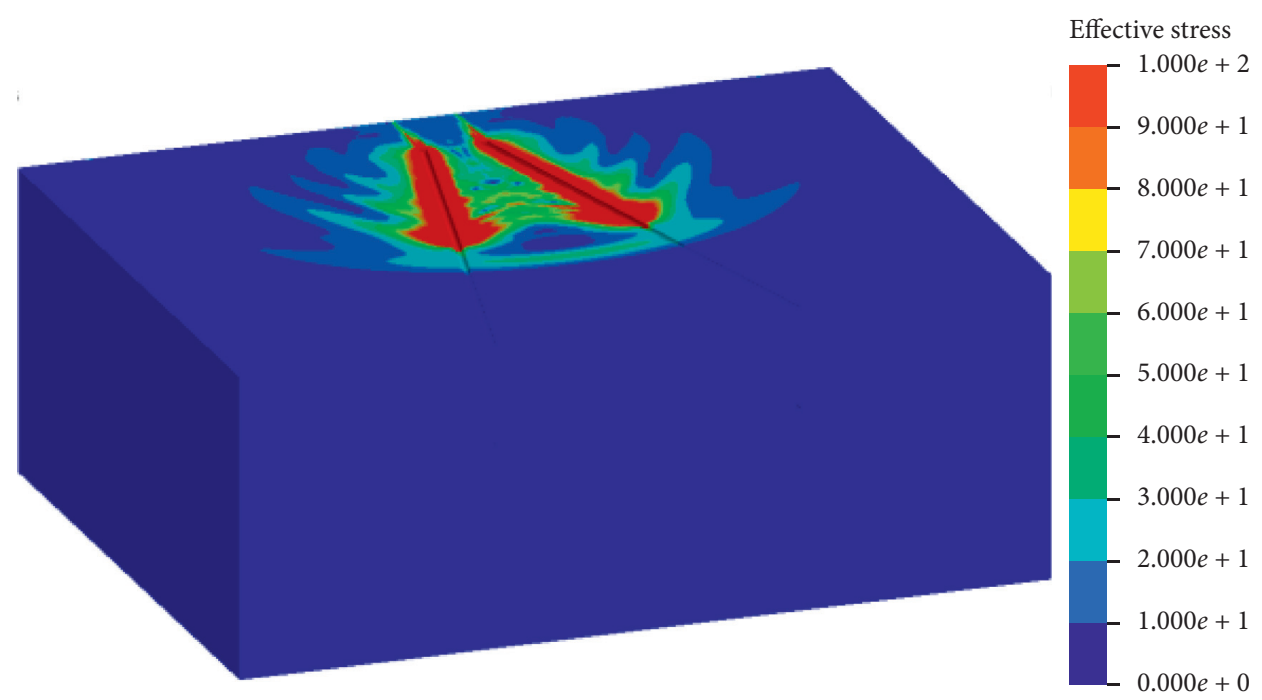

(c)

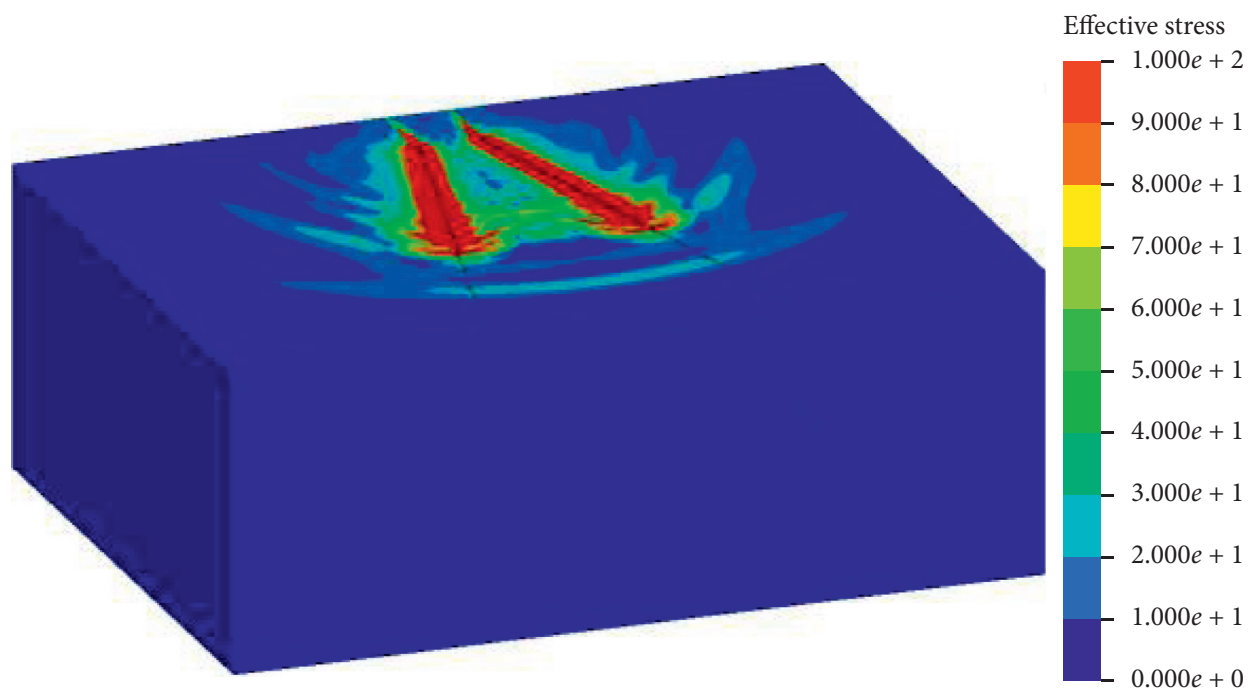

(d)

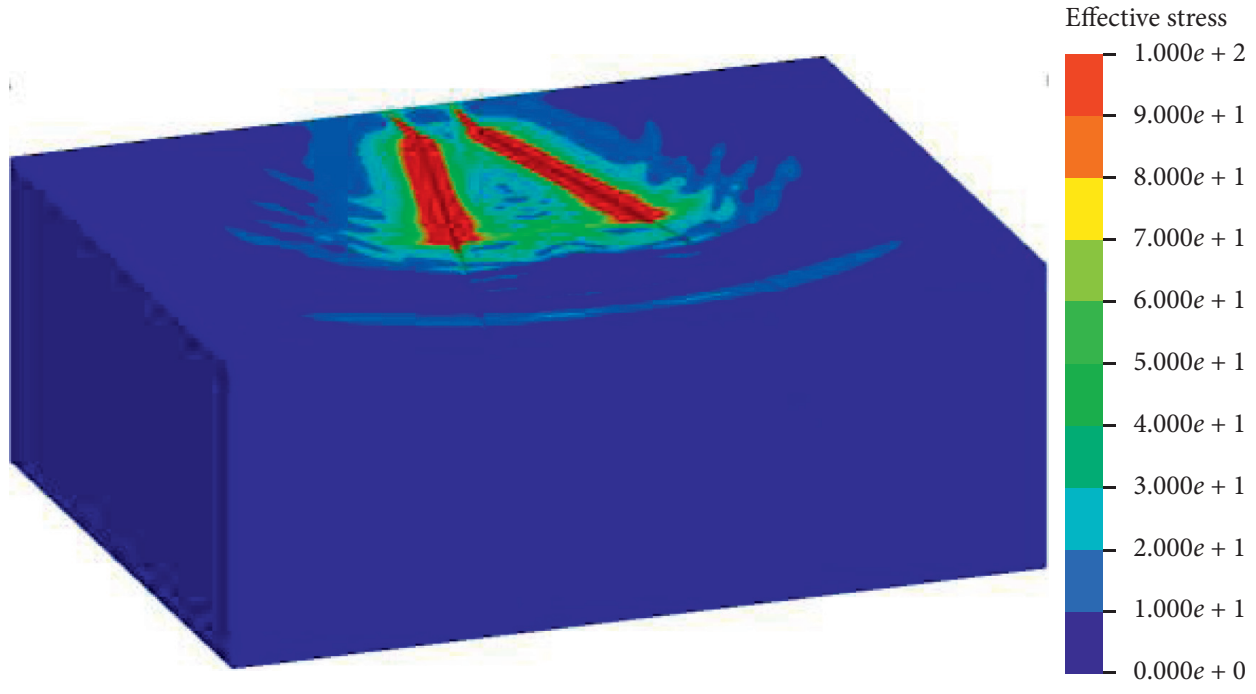

(e)

Figure 5: Continued. 


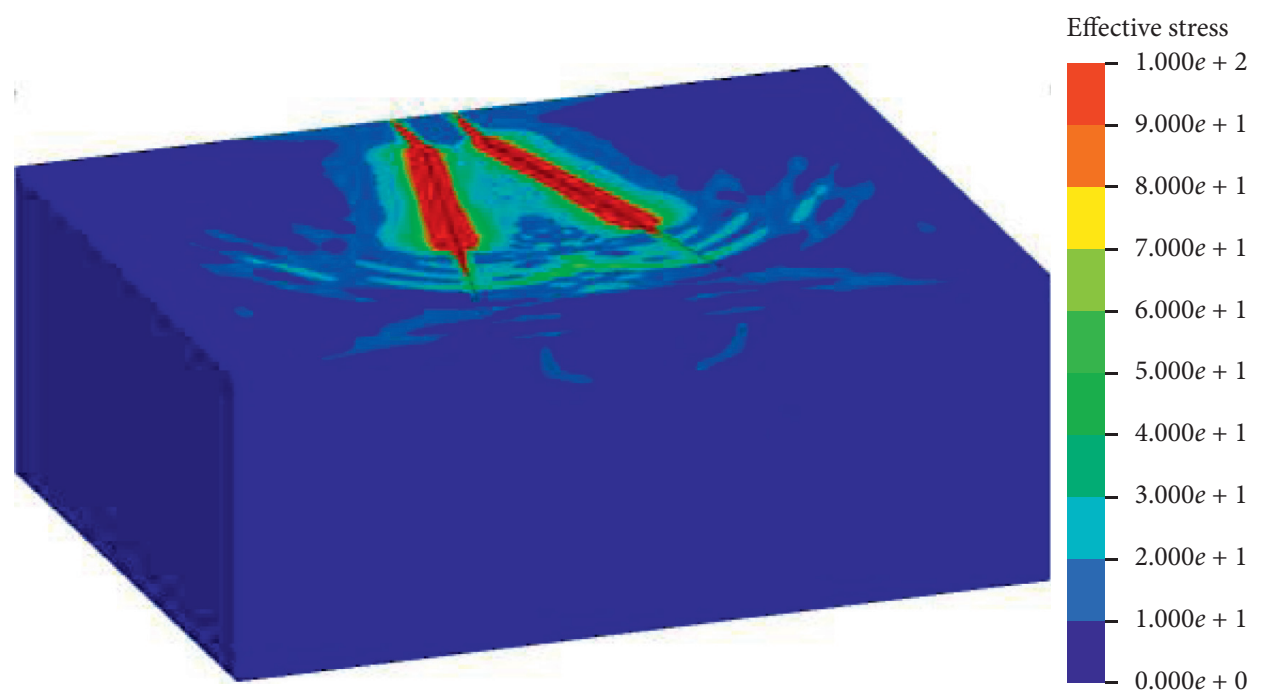

(f)

Figure 5: Effective stress wave evolution of cut blasting model for a small charge diameter. (a) $t=045 \mu \mathrm{s}$; (b) $t=150 \mu \mathrm{s}$; (c) $t=320 \mu \mathrm{s}$; (d) $t=400 \mu \mathrm{s}$; (e) $t=490 \mu \mathrm{s}$; (f) $t=600 \mu \mathrm{s}$.

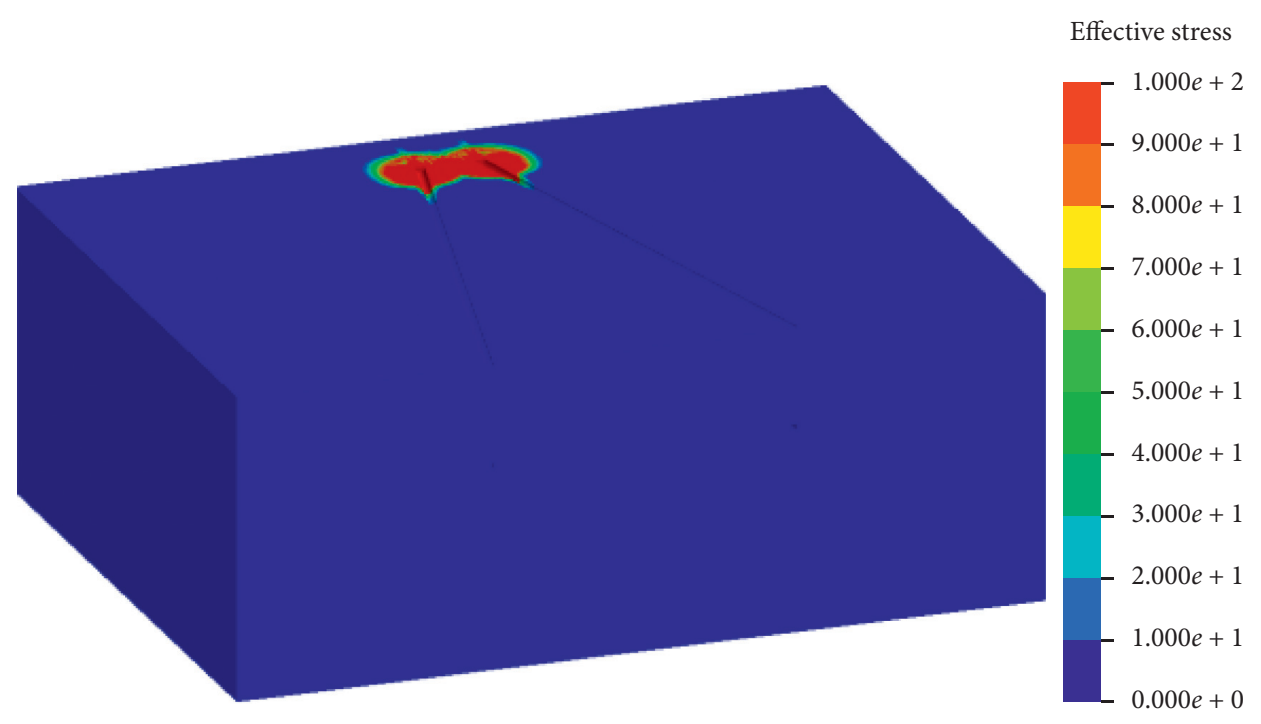

(a)

FIgURE 6: Continued. 


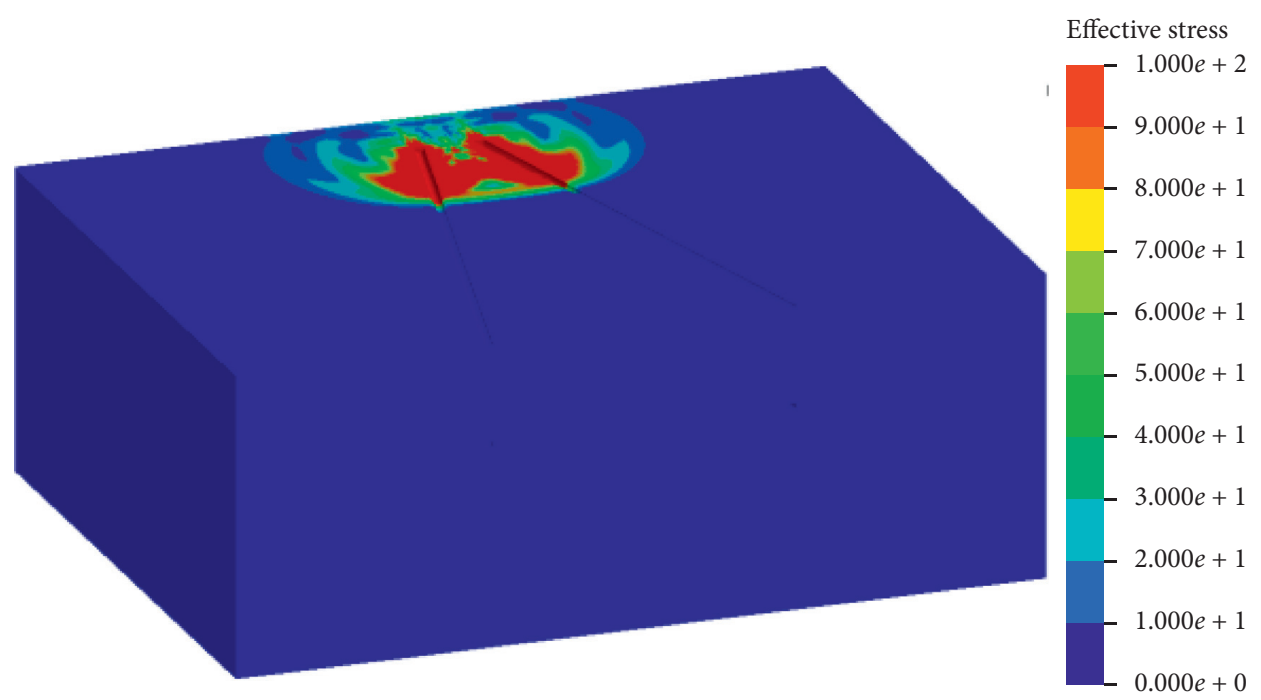

(b)

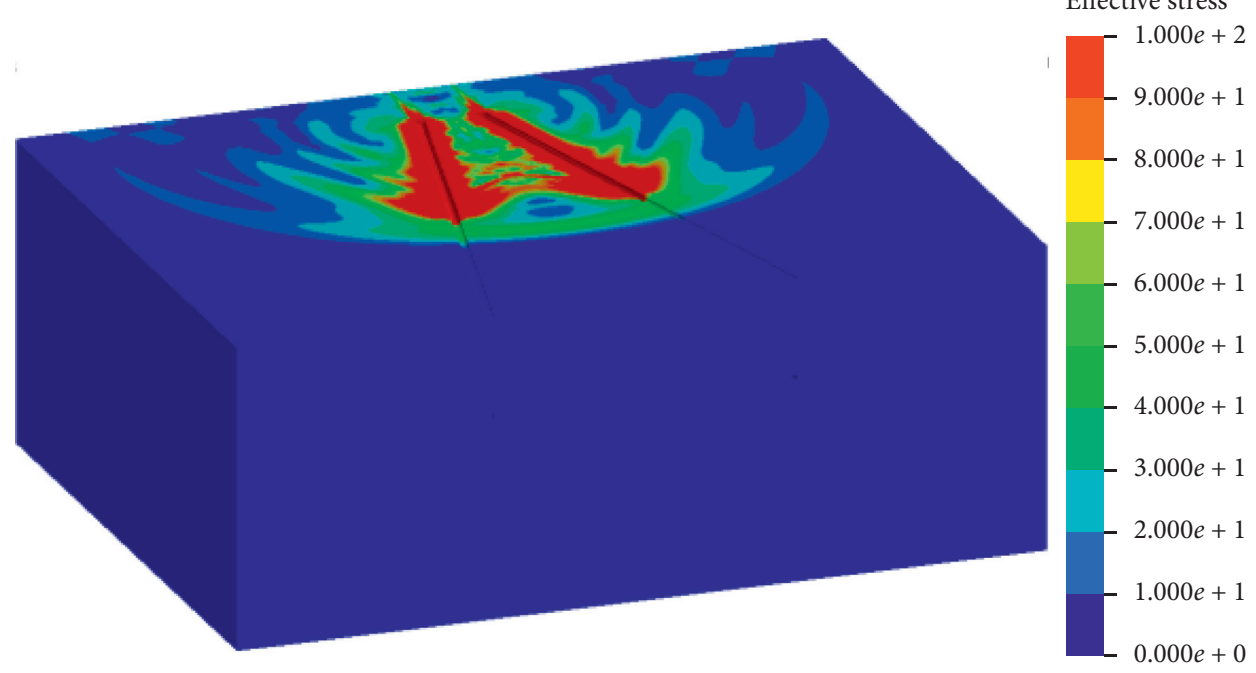

(c)

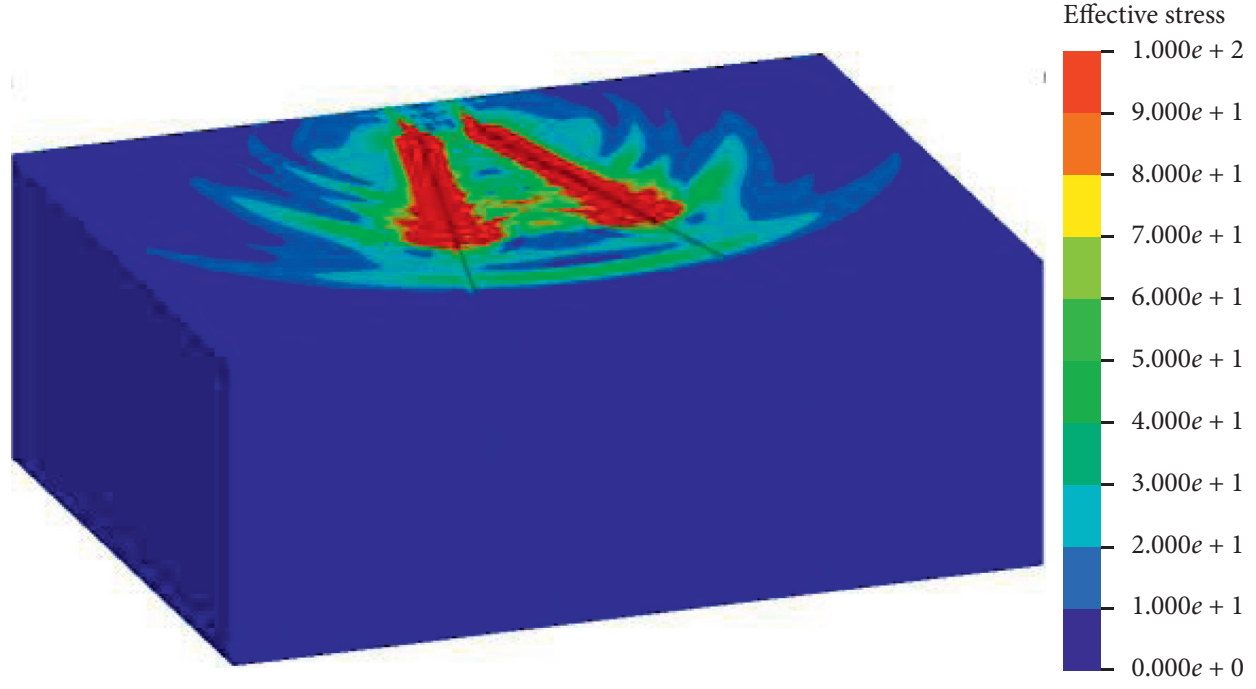

(d)

Figure 6: Continued. 


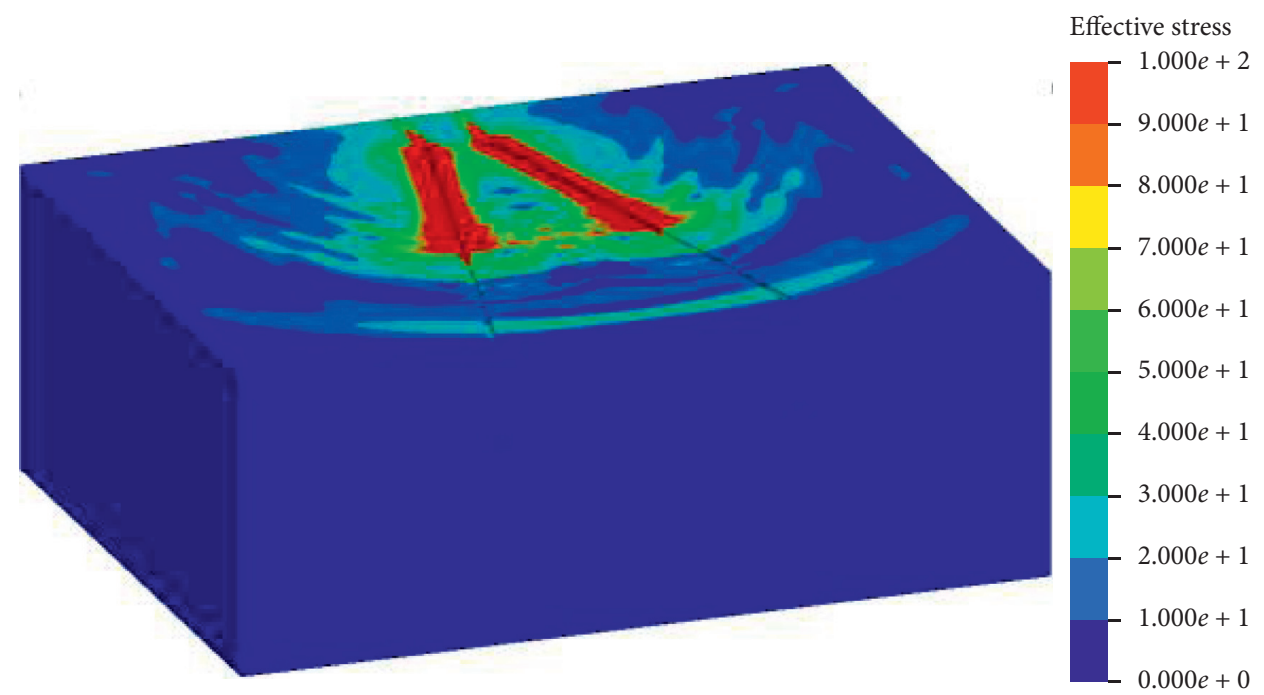

(e)

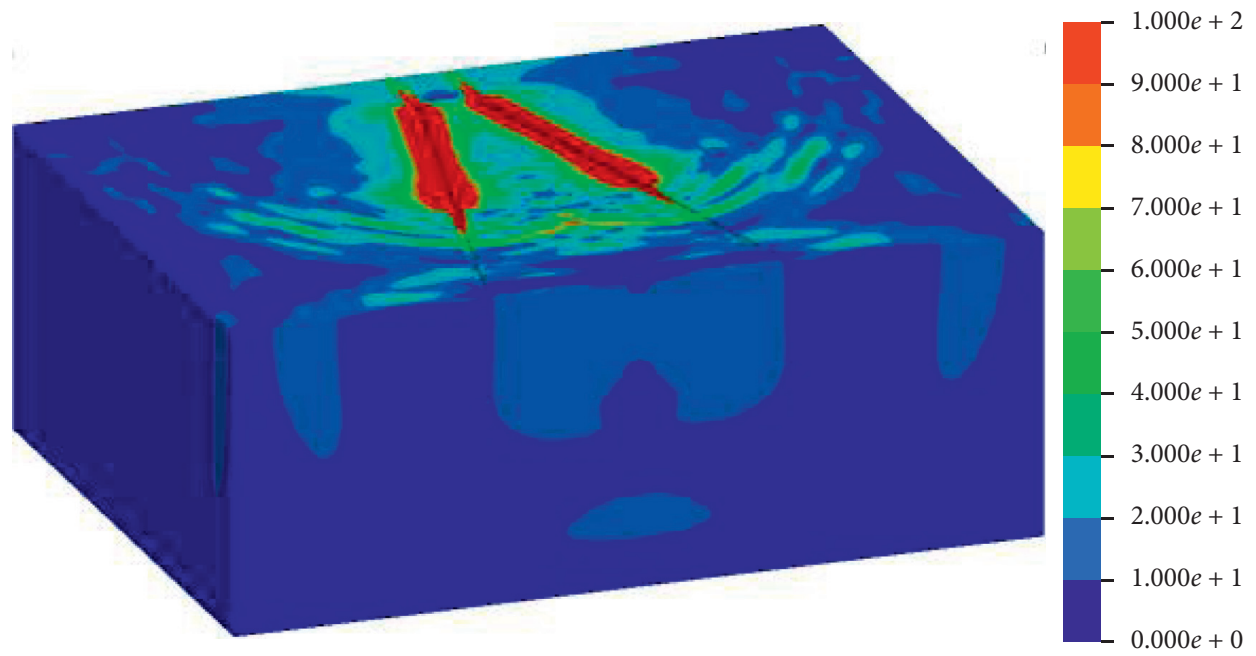

(f)

Figure 6: Effective stress wave evolution of cut blasting model for a large charge diameter. (a) $t=045 \mu \mathrm{s}$. (b) $t=150 \mu \mathrm{s}$. (c) $t=320 \mu \mathrm{s}$. (d) $t=400 \mu \mathrm{s}$. (e) $t=490 \mu \mathrm{s}$. (f) $t=600 \mu \mathrm{s}$.

\section{Field Comparison Tests}

5.1. Test Conditions and Blasting Parameters. To further verify the practicality of cut blasting technology using a large diameter charge, field comparison tests of two cut blasting methods were performed in a hard rock roadway, and the tests for each method were conducted 12 times. The field tests of cut blasting with a small diameter charge were conducted with a blast hole diameter of $42 \mathrm{~mm}$ for the cut holes and other holes and with $35 \mathrm{~mm}$ diameter explosive sticks. During the field tests of cut blasting with a large diameter charge, the cut holes were $50 \mathrm{~mm}$ diameter blast holes and $45 \mathrm{~mm}$ diameter explosive sticks were utilized, while the other holes were $42 \mathrm{~mm}$ diameter blast holes and $35 \mathrm{~mm}$ diameter explosive sticks were utilized.

The field tests were conducted at the $-650 \mathrm{~m}$ level rail roadway of the Panbei Coal Mine in Huainan, Anhui province, China. This rail roadway has a straight wall arch section with a width of $5.4 \mathrm{~m}$, a height of $3.95 \mathrm{~m}$, and a sectional area of $19.03 \mathrm{~m}^{2}$, where the height of the straight wall is $1.1 \mathrm{~m}$. Based on geological survey data, the rock strata are mainly composed of hard fine sandstone with good integrity and few joint fissures, which cause difficulty in cut blasting. The physical and mechanical parameters of fine sandstone have been previously listed in Table 2 .

For the field tests, a dual-arm hydraulic drilling jumbo was used for drilling operations, and class 2 coal mine permissible water-gel explosive sticks with 1-5 segment millisecond delay electric detonators were used as blasting materials. The explosive sticks used were of two specifications: $\quad D 45 \mathrm{~mm} \times L 400 \mathrm{~mm} \times M 700 \mathrm{~g}$ and $D 35 \mathrm{~mm} \times$ $L 330 \mathrm{~mm} \times M 350 \mathrm{~g}$. The blasting parameters for different cut methods are listed in Tables 7 and 8, and the layout of the blast holes is shown in Figure 8. Figure 9 shows some of the relevant construction operations of the field tests. 


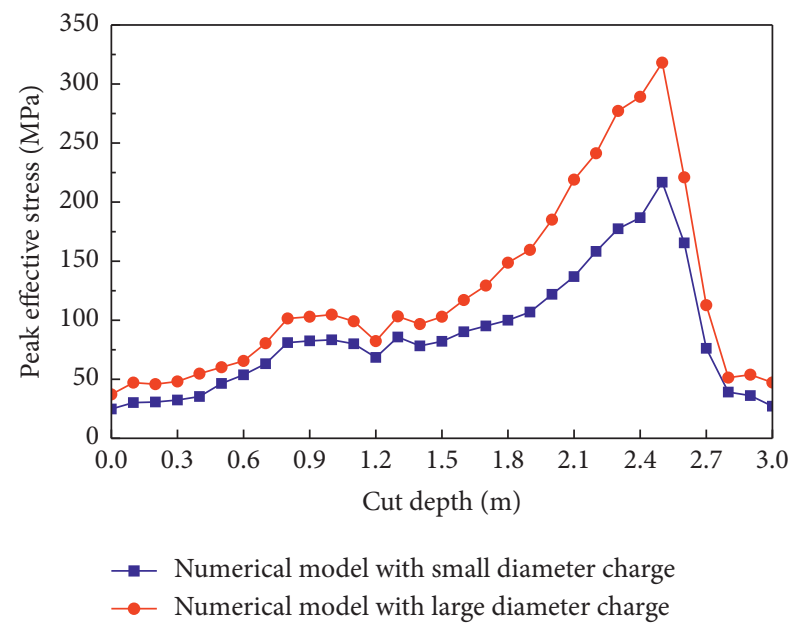

Figure 7: Peak effective stress with cut depth along a central measuring line.

TABle 7: Blasting parameters for cut blasting with a small diameter charge.

\begin{tabular}{|c|c|c|c|c|c|c|c|}
\hline \multirow[b]{2}{*}{ Hole name } & \multirow[b]{2}{*}{ Hole no. } & \multirow[b]{2}{*}{ Number of holes } & \multirow[b]{2}{*}{ Hole diameter (mm) } & \multirow[b]{2}{*}{ Charge diameter (mm) } & \multicolumn{2}{|c|}{ Charge quantity } & \multirow[b]{2}{*}{$\begin{array}{c}\text { Detonator } \\
\text { order }\end{array}$} \\
\hline & & & & & $\begin{array}{c}\text { Explosive volume } \\
\text { per hole }\end{array}$ & $\begin{array}{c}\text { Total } \\
\text { weight }(\mathrm{kg})\end{array}$ & \\
\hline Cut hole & $1-6$ & 6 & 42 & 35 & 4.0 & 8.40 & 1 \\
\hline Auxiliary hole & $7-14$ & 8 & 42 & 35 & 3.0 & 8.40 & 2 \\
\hline Auxiliary hole & $15-25$ & 11 & 42 & 35 & 3.0 & 11.55 & 3 \\
\hline Auxiliary hole & $26-39$ & 14 & 42 & 35 & 3.0 & 14.70 & 4 \\
\hline Peripheral hole & $40-60$ & 21 & 42 & 35 & 2.0 & 14.70 & 5 \\
\hline Bottom hole & $61-68$ & 8 & 42 & 35 & 3.0 & 8.40 & 5 \\
\hline Total & - & 68 & - & - & - & 66.15 & - \\
\hline
\end{tabular}

TABLE 8: Blasting parameters for cut blasting with a large diameter charge.

\begin{tabular}{|c|c|c|c|c|c|c|c|}
\hline \multirow[b]{2}{*}{ Hole name } & \multirow[b]{2}{*}{$\begin{array}{l}\text { Hole } \\
\text { no. }\end{array}$} & \multirow[b]{2}{*}{$\begin{array}{l}\text { Number of } \\
\text { holes }\end{array}$} & \multirow[b]{2}{*}{$\begin{array}{l}\text { Hole diameter } \\
\qquad(\mathrm{mm})\end{array}$} & \multirow[b]{2}{*}{$\begin{array}{l}\text { Charge diameter } \\
(\mathrm{mm})\end{array}$} & \multicolumn{2}{|c|}{ Charge quantity } & \multirow[b]{2}{*}{$\begin{array}{l}\text { Detonator } \\
\text { order }\end{array}$} \\
\hline & & & & & $\begin{array}{c}\text { Explosive volume per } \\
\text { hole }\end{array}$ & $\begin{array}{l}\text { Total weight } \\
(\mathrm{kg})\end{array}$ & \\
\hline Cut hole & $1-6$ & 6 & 50 & 45 & 3.3 & 13.86 & 1 \\
\hline Auxiliary hole & $7-14$ & 8 & 42 & 35 & 3.0 & 8.40 & 2 \\
\hline Auxiliary hole & $15-25$ & 11 & 42 & 35 & 3.0 & 11.55 & 3 \\
\hline Auxiliary hole & $26-39$ & 14 & 42 & 35 & 3.0 & 14.70 & 4 \\
\hline $\begin{array}{l}\text { Peripheral } \\
\text { hole }\end{array}$ & $40-60$ & 21 & 42 & 35 & 2.0 & 14.70 & 5 \\
\hline Bottom hole & $61-68$ & 8 & 42 & 35 & 3.0 & 8.40 & 5 \\
\hline Total & - & 68 & - & - & - & 71.61 & - \\
\hline
\end{tabular}

5.2. Results of Field Tests. Comparative data of the blasting effects are presented in Table 9. For the $42 \mathrm{~mm}$ diameter blast holes with $35 \mathrm{~mm}$ diameter explosive sticks used for cut blasting, the average footage is $1.9 \mathrm{~m}$, and the average utilization rate of the blast holes is $79.2 \%$. For the $50 \mathrm{~mm}$ diameter blast holes with $45 \mathrm{~mm}$ diameter explosive sticks used for cut blasting, the average footage reaches $2.2 \mathrm{~m}$, and the average utilization rate of the blast holes reaches $91.7 \%$. Thus, in contrast to cut blasting with the small diameter charge, the average footage is increased by $0.30 \mathrm{~m}$, and the average utilization rate of blast holes is increased by $12.5 \%$, with the large diameter charge.
The results of field comparison tests indicate that the use of a large diameter charge can improve the cut effect in hard rock roadway and hence increase the blasting footage and the utilization rate of blast holes.

\section{Discussion}

In rock blasting engineering, the effective energy used for rock breaking and rock excavation accounts for about $60 \sim 70$ percent of the total blasting energy, and the remaining energy results in blast hazards [56]. As mentioned in Section 2 , with the blast hole as the center, there are the crushing 

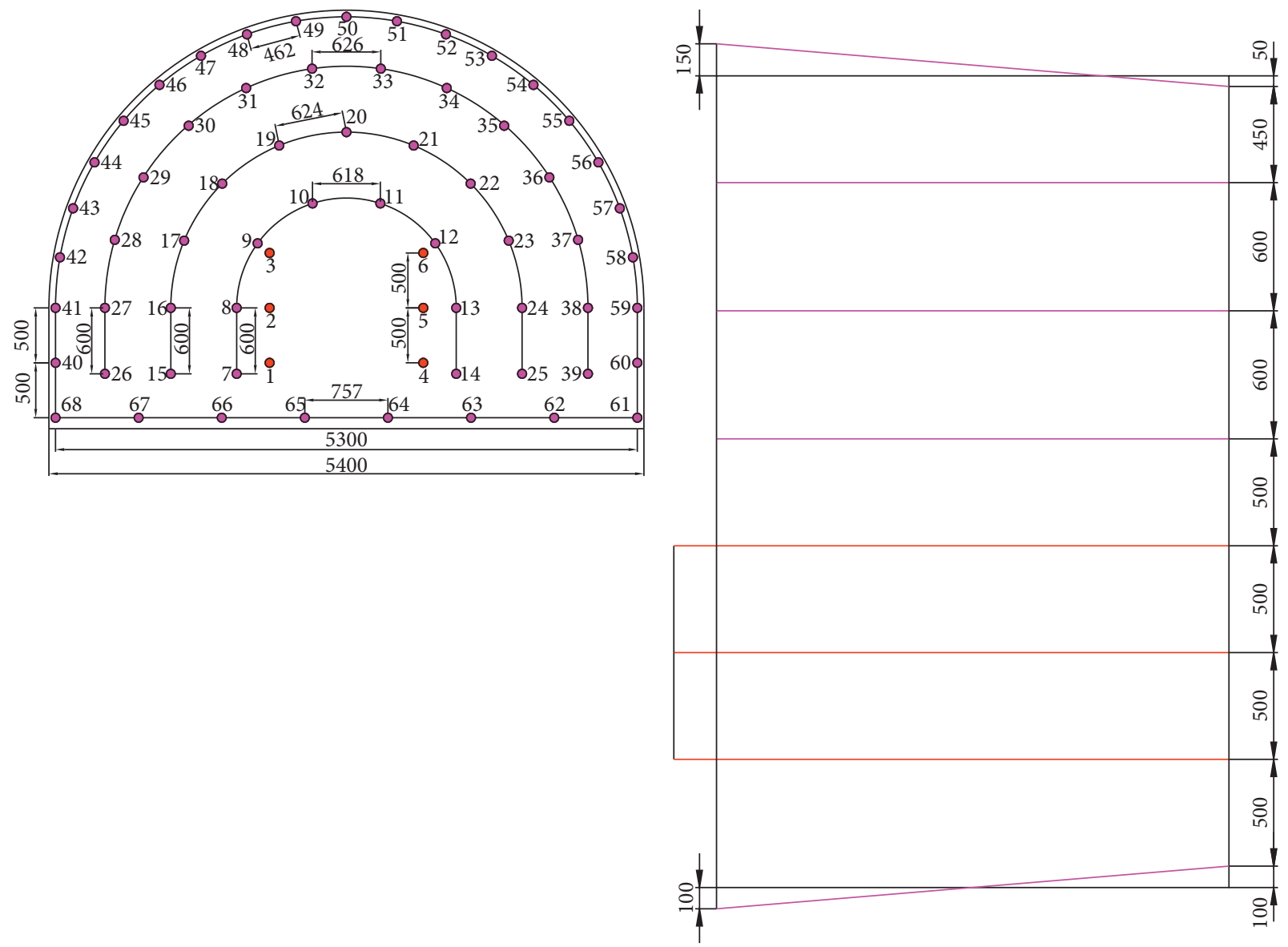

(a)

(b)

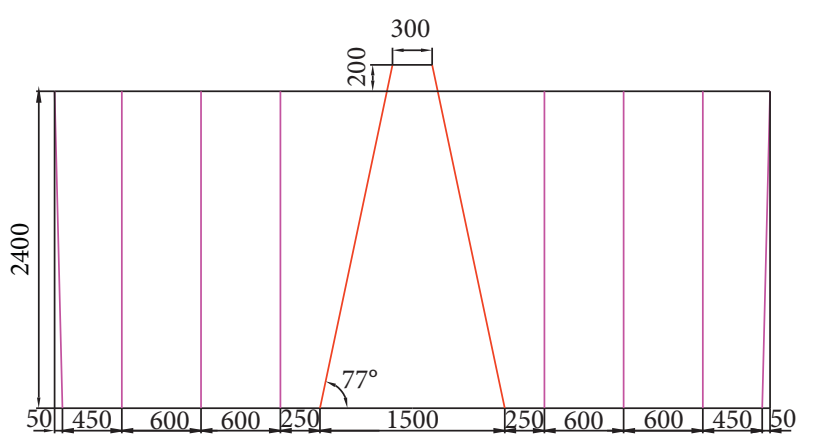

(c)

FIgURE 8: Blast hole layout (unit: mm). (a) Front view. (b) Left view. (c) Top view.

zone, the cracking zone, and the vibration zone. The blasting vibration from roadway excavation might negatively impact the stability of surrounding rocks and supporting structures.

Blasting vibration is usually expressed by the particle vibration velocity, which can be calculated from Sadov's formula as follows:

$$
V=K_{1}\left(\frac{W^{(1 / 3)}}{R_{m}}\right)^{\alpha_{3}}
$$

where $V$ is the particle vibration velocity; $R_{m}$ is the distance from the blasting source; $W$ is the single blasting charge quantity; $K_{1}$ and $\alpha_{3}$ are the coefficient and attenuation exponent associated with geological conditions, respectively.

According to equation (21), for identical geological conditions and distances from the source, the blasting vibration depends only on the single blasting charge quantity. The use of large diameter charges implies an increase in the single blasting charge quantity, which leads to an increase in particle vibration velocity. However, for the case presented in this study, after the use of a large diameter charge, the single blasting charge quantity of cut blasting increased from $8.40 \mathrm{~kg}$ to $13.86 \mathrm{~kg}$, which is still less than the maximum single blasting charge quantity of $23.10 \mathrm{~kg}$. It can be seen that 


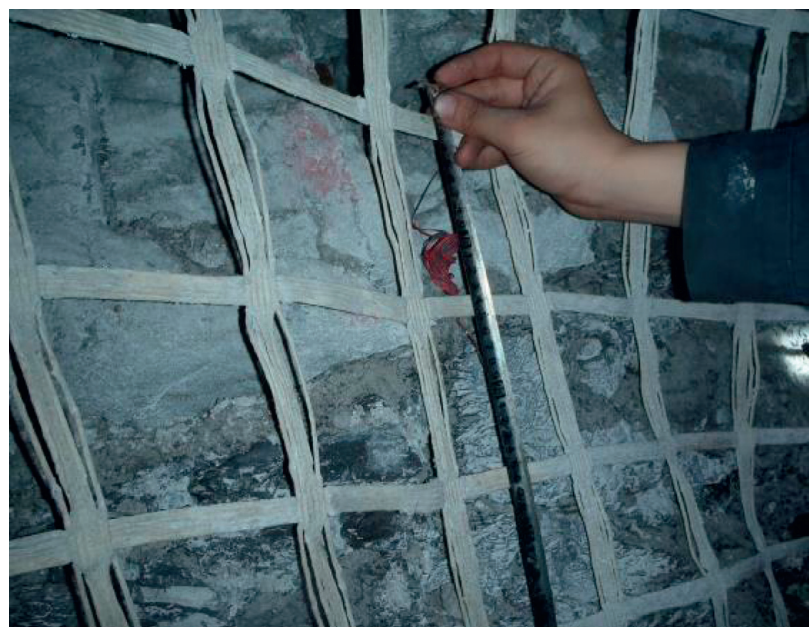

(a)

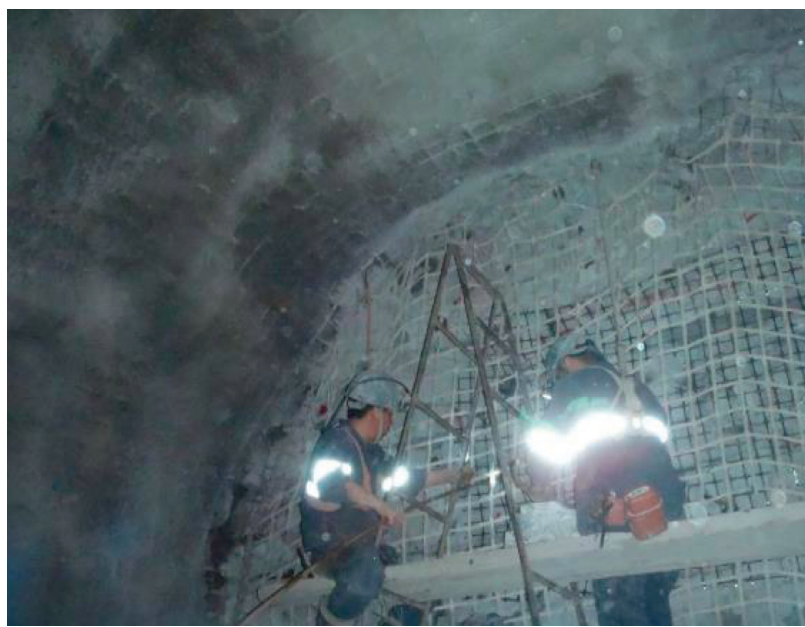

(c)

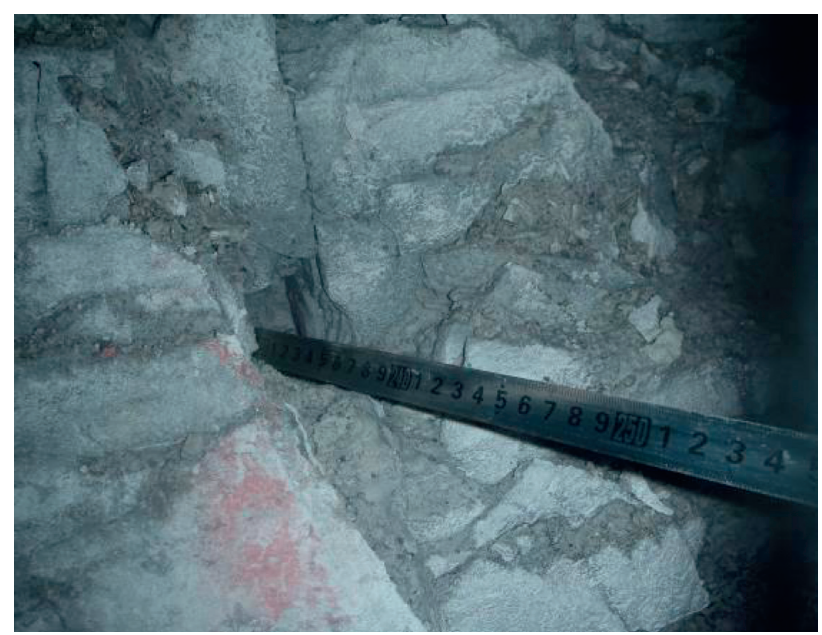

(b)

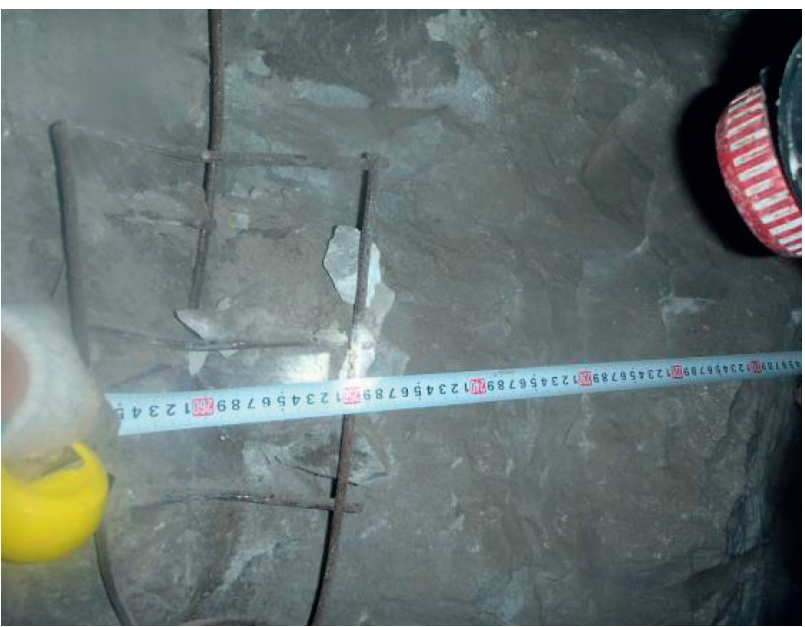

(d)

Figure 9: Construction operations of field tests. (a) Check of hole space. (b) Check of hole depth. (c) Charge of blast holes. (d) Measurement of footage.

TABLe 9: Comparative data of blasting effects.

\begin{tabular}{|c|c|c|c|c|}
\hline \multirow{2}{*}{ No. } & \multicolumn{2}{|c|}{ Cut blasting with small diameter charge } & \multicolumn{2}{|c|}{ Cut blasting with large diameter charge } \\
\hline & Footage (m) & Utilization rate of blast hole (\%) & Footage $(\mathrm{m})$ & Utilization rate of blast hole (\%) \\
\hline 1 & 1.95 & 81.3 & 2.20 & 91.7 \\
\hline 2 & 1.90 & 79.2 & 2.20 & 91.7 \\
\hline 3 & 1.90 & 79.2 & 2.15 & 89.6 \\
\hline 4 & 1.90 & 79.2 & 2.25 & 93.8 \\
\hline 5 & 1.85 & 77.1 & 2.15 & 89.6 \\
\hline 6 & 1.90 & 79.2 & 2.20 & 91.7 \\
\hline 7 & 1.95 & 81.3 & 2.25 & 93.8 \\
\hline 8 & 1.85 & 77.1 & 2.20 & 91.7 \\
\hline 9 & 1.85 & 77.1 & 2.15 & 89.6 \\
\hline 10 & 1.90 & 79.2 & 2.25 & 93.8 \\
\hline 11 & 1.95 & 81.3 & 2.20 & 91.7 \\
\hline 12 & 1.90 & 79.2 & 2.20 & 91.7 \\
\hline Average & 1.90 & 79.2 & 2.20 & 91.7 \\
\hline
\end{tabular}


the blasting vibration generated by cut blasting with large diameter charges is within a controllable range.

\section{Conclusions}

(1) Based on theoretical analysis, the radii of the crushing and cracking zones caused by a $50 \mathrm{~mm}$ diameter blast hole and a $45 \mathrm{~mm}$ diameter explosive stick are 1.31 times that caused by a $42 \mathrm{~mm}$ diameter blast hole and a $35 \mathrm{~mm}$ diameter explosive stick. Further penetration of blasting cracks can be realized by a large diameter charge to enhance the fragmentation degree of the rock mass in the cut cavity. The cavity formation power generated by a $50 \mathrm{~mm}$ diameter blast hole and a $45 \mathrm{~mm}$ diameter explosive stick is 2.22 times that generated by a $42 \mathrm{~mm}$ diameter blast hole and a $35 \mathrm{~mm}$ diameter explosive stick. For constant cavity formation resistance, a large diameter charge is conducive to expelling the rock mass fragments from the cut cavity.

(2) Simulation results can depict the formation of stress wave in wedge cut blasting for different charge diameters. The maximum and average values of peak effective stress at measuring points along the central measuring line of the numerical model with a large diameter charge are $46.7 \%$ and $41.5 \%$ higher, respectively, than those obtained from the numerical model with a small diameter charge. The use of a large diameter charge in cut holes can increase the stress field intensity in the cut cavity and hence increase the extent of damage to the rock mass.

(3) A comparison of the blasting effects after field tests shows an average footage of $2.20 \mathrm{~m}$ and an average utilization rate of blast holes of $91.7 \%$ for $50 \mathrm{~mm}$ diameter blast holes and $45 \mathrm{~mm}$ diameter explosive sticks used in cut blasting, which represent an average increase in footage of $0.30 \mathrm{~m}$ and an average increase in the utilization rate of blast holes of $12.5 \%$ over cut blasting with $42 \mathrm{~mm}$ blast holes and $35 \mathrm{~mm}$ diameter explosive sticks. Thus, the cutting effects in hard rock roadways can be improved with the use of large diameter charges, which increase the blasting footage and the utilization rate of blast holes.

\section{Data Availability}

The data used to support the findings of this study are available from the corresponding author upon reasonable request.

\section{Conflicts of Interest}

The authors declare that they have no conflicts of interest.

\section{Acknowledgments}

This work was financially supported by the National Natural Science Foundation of China (Grants nos. 51374012 and 51404010), the Natural Science Research Project of Anhui
Universities (Grant no. KJ2017ZD11), and the Patent Transformation Project of Anhui University of Science and Technology (Grant no. ZL201908). In addition, thanks are due to all the people who contributed to the research and the manuscript.

\section{References}

[1] R. S. Yang, C. X. Ding, L. Y. Yang, Z. Lei, and C. D. Zheng, "Study of decoupled charge blasting based on high-speed digital image correlation method," Tunnelling and Underground Space Technology, vol. 83, pp. 51-59, 2019.

[2] J. Zhou, M. Koopialipoor, B. R. Murlidhar et al., "Use of intelligent methods to design effective pattern parameters of mine blasting to minimize flyrock distance," Natural Resources Research, vol. 29, no. 2, pp. 625-639, 2020.

[3] Y. Luo, F. Q. Gong, X. B. Li, and S. Y. Wang, "Experimental simulation investigation of influence of depth on spalling characteristics in circular hard rock tunnel," Journal of Central South University, vol. 27, no. 3, pp. 891-910, 2020.

[4] L. X. Xie, W. B. Lu, Q. B. Zhang, Q. H. Jiang, M. Chen, and J. Zhao, "Analysis of damage mechanisms and optimization of cut blasting design under high in-situ stresses," Tunnelling and Underground Space Technology, vol. 66, pp. 19-33, 2017.

[5] D. Q. Yang, X. G. Wang, Y. J. Wang, H. M. An, and Z. Lei, "Experiment and analysis of wedge cutting angle on cutting effect," Advances in Civil Engineering, vol. 2020, Article ID 5126790, 16 pages, 2020.

[6] M. Gong, B. Wen, and H. Wang, "Influence of cut parameters on blasting effect in rock roadway of coal mine," Explosive and Shock Waves, vol. 35, no. 4, pp. 576-584, 2015.

[7] T. Liao, C. J. Pu, J. Q. Wang, R. Jiang, X. Yang, and X. F. Chen, "Model experiment and analysis of wedge-shaped cutting blasting with cutting seam cartridge in rock tunnel," Metal Mine, vol. 44, no. 2, pp. 40-44, 2015.

[8] V. Y. Shapiro, "Efficiency of cut configuration in driving tunnels with a set of deep blast holes," Soviet Mining Science, vol. 25, no. 4, pp. 379-386, 1989.

[9] J. Dai and X. L. Du, "Research on blasting parameters of wedge-shaped cutting for rock tunnel," Mining Research and Development, vol. 32, no. 2, pp. 90-93, 2011.

[10] M. Cardu and J. Seccatore, "Quantifying the difficulty of tunnelling by drilling and blasting," Tunnelling and Underground Space Technology, vol. 60, pp. 178-182, 2016.

[11] X. K. Zou, J. C. Zhang, Q. Pan, and W. Wang, "Vibration reduction effect of stepped V-cut blasting," Journal of Southwest Jiaotong University, vol. 53, no. 3, pp. 450-458, 2018.

[12] C. J. Pu, T. Liao, D. J. Xiao, J. Q. Wang, and R. Jiang, "Grey relation analysis of influence factors on rock tunnel wedgeshaped cut blasting," Industrial Minerals \& Processing, vol. 45, no. 3, pp. 34-38, 2016.

[13] Z. R. Zhang and R. S. Yang, "Multi-step cutting technology and its application in rock roadways," Chinese Journal of Rock Mechanics and Engineering, vol. 30, no. 3, pp. 551-559, 2019.

[14] W. M. Liang, Y. X. Wang, H. B. Chu, and X. L. Yang, "Study on effect of symmetry of w edge shaped cutting hole angle on cut blasting," Metal Mine, vol. 38, no. 11, pp. 21-24, 2009.

[15] R. L. Shan, B. L. Huang, Z. T. Wei, and X. S. Kong, "Model test of quasi-parallel cut blasting in rock drivage," Chinese Journal of Rock Mechanics and Engineering, vol. 31, no. 2, pp. 256-264, 2012.

[16] W. H. Yuan, Q. Y. Ma, and W. Huang, "Model experiment and analysis of wedge-shaped cutting millisecond blasting," 
Chinese Journal of Rock Mechanics and Engineering, vol. 31, no. S1, pp. 3352-3356, 2012.

[17] K. Man, X. L. Liu, J. Wang, and X. Y. Wang, "Blasting energy analysis of the different cutting methods," Shock and Vibration, vol. 2018, Article ID 9419018, 13 pages, 2018.

[18] G. L. Yang, L. L. Jiang, and R. S. Yang, "Investigation of cut blasting with duplex wedge deep holes," Journal of China University of Mining \& Technology, vol. 42, no. 5, pp. 755-760, 2013.

[19] J. H. Hu, C. Yang, K. P. Zhou, B. R. Zhou, and S. G. Zhang, "Experimental study and application of medium-length hole blasting technique in coal-rock roadway," Journal of Central South University (Science and Technology), vol. 48, no. 4, pp. 3309-3315, 2017.

[20] Q. Zong, Y. D. Ma, and H. B. Wang, "Large diameter hole blasting experimental in hard rock roadway of coalmine," Blasting, vol. 34, no. 1, pp. 47-51, 2017.

[21] S. Esen, I. Onederra, and H. A. Bilain, "Modelling the size of the crushed zone around a blasthole," Journal of Rock Mechanics and Mining Sciences, vol. 40, no. 6, pp. 485-495, 2003.

[22] P. Yan, W. X. Zhou, W. B. Lu, M. Chen, and C. B. Zhou, "Simulation of bench blasting considering fragmentation size distribution," International Journal of Impact Engineering, vol. 90, pp. 132-145, 2016.

[23] Y. Yuan, C. F. Yuan, C. Zhu, H. X. Liu, and S. Z. Wang, "Study on the disaster reduction mechanism of presplitting blasting and reasonable blasting parameters for shallowly buried remnant pillars," Energy Science \& Engineering, vol. 7, pp. 2884-2894, 2019.

[24] Z. K. Wang, X. W. Gu, W. L. Zhang, Q. K. Xie, X. C. Xu, and Q. Wang, "Analysis of the cavity formation mechanism of wedge cut blasting in hard rock," Shock and Vibration, vol. 2019, Article ID 1828313, 10 pages, 2019.

[25] D. P. Blair, "Seismic radiation from an explosive column," Geophysics, vol. 75, no. 1, pp. 55-65, 2010.

[26] W. L. Wang, Drilling and Blasting, China Coal Industry Press, Beijing, China, 1984.

[27] J. H. Yang, C. Yao, Q. H. Jiang, W. B. Lu, and S. H. Jiang, “2D numerical analysis of rock damage induced by dynamic insitu stress redistribution and blast loading in underground blasting excavation," Tunnelling and Underground Space Technology, vol. 70, pp. 221-232, 2017.

[28] J. Dai, "Calculation of radii of the broken and carcked areas in rock by a long charge explosion," Journal of Liaoning Technical University (Nature Science), vol. 20, no. 2, pp. 144-147, 2001.

[29] L. Wu, W. B. Lu, and Q. Zong, "Distribution of explosive energy consumed by column charge in rock," Rock and Soil Mechanics, vol. 27, no. 5, pp. 735-739, 2006.

[30] F. Q. Gong, H. Ye, and Y. Luo, "Rate effect on the burst tendency of coal-rock combined body under low loading rate range," Journal of China Coal Society, vol. 42, no. 11, pp. 2258-2260, 2017.

[31] F. Q. Gong, J. Wang, and X. B. Li, "The rate effect of compression characteristics and a unified model of dynamic increasing factor for rock materials," Chinese Journal of Rock Mechanics and Engineering, vol. 37, no. 7, pp. 1586-1595, 2018.

[32] F. Q. Gong, X. F. Si, X. B. Li, and S. Y. Wang, "Dynamic triaxial compression tests on sandstone at high strain rates and low confining pressures with split Hopkinson pressure bar," International Journal of Rock Mechanics and Mining Sciences, vol. 113, pp. 211-219, 2019.
[33] X. F. Si, F. Q. Gong, X. B. Li, S. Y. Wang, and S. Luo, “Dynamic Mohr-Coulomb and Hoek-Brown strength criteria of sandstone at high strain rates," International Journal of Rock Mechanics and Mining Sciences, vol. 115, no. 5, pp. 48-59, 2019.

[34] F. Q. Gong, D. H. Lu, X. B. Li, and Q. H. Rao, "Experimental research of sandstone dynamic strength criterion under different strain rates," Rock and Soil Mechanics, vol. 34, no. 9, pp. 2433-2441, 2013.

[35] Z. W. Ding, J. D. Jia, X. F. Li, J. Li, Y. L. Li, and J. L. Liao, "Experimental study and application of medium-length hole blasting technique in coal-rock roadway," Energy Science \& Engineering, vol. 8, pp. 1554-1566, 2020.

[36] R. L. Shan, B. L. Huang, W. J. Gao, Y. Zhu, and X. Y. Hao, "Case studies of new technology application of quasi-parallel cut blasting in rock roadway drivage," Chinese Journal of Rock Mechanics and Engineering, vol. 30, no. 4, pp. 225-232, 2011.

[37] C. G. Huang, Y. B. Zhang, J. F. He, Y. J. Luo, and R. J. Sun, "Permeability improvements of an outburst-prone coal seam by means of presplitting and blasting with multiple deep boreholes," Energy Science \& Engineering, vol. 7, pp. 22232236, 2019.

[38] Y. G. Hu, W. B. Lu, M. Chen, P. Yan, and J. H. Yang, "Comparison of blast-induced damage between presplit and smooth blasting of high rock slope," Rock Mechanics and Rock Engineering, vol. 47, pp. 1307-1320, 2014.

[39] X. P. Li, J. L. Lv, J. H. Huang, Y. Luo, and T. T. Liu, "Numerical simulation research of smooth wall blasting using the timing sequence control method under different primary blast hole shapes," Shock and Vibration, vol. 2019, Article ID 2425904, 16 pages, 2019.

[40] K. Liu, Q. Y. Li, C. Q. Wu, X. B. Li, and J. Li, "A study of cut blasting for one-step raise excavation based on numerical simulation and field blast tests," International Journal of Rock Mechanics and Mining Sciences, vol. 109, pp. 91-104, 2018.

[41] B. Cheng, H. B. Wang, and Q. Zong, "Numerical simulation on blasting mechanism of slotted cartridge based on coupled SPH-FEM algorithm," Chinese Journal of Energetic Materials, vol. 28, no. 4, pp. 330-307, 2020.

[42] Q. Zong, B. Cheng, and H. B. Wang, "Numerical simulation of pressure on borehole wall and damage effect with eccentric decoupled charge," Blasting, vol. 36, no. 3, pp. 76-83, 2019.

[43] D. P. Blair, "Acoustic pulse transmission in half-spaces and finite-length cylindrical rods," Geophysics, vol. 50, no. 11, pp. 1676-1683, 1985.

[44] D. P. Blair, "The free surface influence on blast vibration," International Journal of Rock Mechanics and Mining Sciences, vol. 77, pp. 182-191, 2015.

[45] J. H. Yang, J. Y. Cai, C. Yao, P. Li, Q. H. Zhang, and C. B. Zhou, "Comparative study of tunnel blast-induced vibration on tunnel surfaces and inside surrounding rock," Rock Mechanics and Rock Engineering, vol. 52, no. 11, pp. 47474761, 2019.

[46] M. Jin, Y. F. Hao, and H. Hao, "Numerical study of fence type blast walls for blast load mitigation," International Journal of Impact Engineering, vol. 131, pp. 238-255, 2019.

[47] C. P. Yi, D. Johansson, and J. Greberg, "Effects of in-situ stresses on the fracturing of rock by blasting," Computers and Geotechnics, vol. 104, pp. 321-330, 2018.

[48] J. P. Zuo, Z. D. Li, S. K. Zhao, Y. Q. Jiang, H. Y. Liu, and M. H. Yao, "A study of fractal deep-hole blasting and its induced stress behavior of hard roof strata in bayangaole coal mine, China," Advances in Civil Engineering, vol. 2019, Article ID 9504101, 14 pages, 2019. 
[49] Y. Z. Yang, Z. S. Shao, J. F. Mi, and X. F. Xiong, "Effect of adjacent hole on the blast-induced stress concentration in rock blasting," Advances in Civil Engineering, vol. 2018, Article ID 5172878, 13 pages, 2018.

[50] Z. L. Wang, Y. C. Li, and R. F. Shen, "Numerical simulation of tensile damage and blast crater in brittle rock due to underground explosion," International Journal of Rock Mechanics and Mining Sciences, vol. 44, no. 5, pp. 730-738, 2007.

[51] H. B. Li, X. Xia, J. C. Li, J. Zhao, B. Liu, and Y. Q. Liu, "Rock damage control in bedrock blasting excavation for a nuclear power plant," International Journal of Rock Mechanics \& Mining Sciences, vol. 48, pp. 210-218, 2011.

[52] Y. Shu, P. Shao, C. Dong, Z. Cao, and X. W. Yi, "Influence of rock strength on the propagation of slotted cartridge blastinginduced directional cracks," Advances in Civil Engineering, vol. 2019, Article ID 5752189, 12 pages, 2019.

[53] J. P. Zuo, Y. J. Sun, W. G. Liu, and B. Hu, "Mechanical analysis and blasting mechanism of main roof initial fracturing in shallow depth mining face with large cutting height," Journal of China Coal Society, vol. 41, no. 9, pp. 2165-2172, 2016.

[54] P. F. Guo, K. K. Ye, J. B. Bai, and X. H. Zhang, "Numerical simulation research on crack bifurcation mechanism of bidirectional cumulative tensile blasting," Advances in Civil Engineering, vol. 2020, Article ID 5785296, 19 pages, 2020.

[55] K. Wang, X. M. Qian, and Z. Y. Liu, "Experimental and numerical investigations on predictor equations for determining parameters of blasting-vibration on underground gas pipe networks," Process Safety and Environmental Protection, vol. 133, pp. 315-331, 2020.

[56] W. B. Gu, Z. X. Wang, J. H. Chen, J. Q. Liu, and M. Lu, "Experimental and theoretical study on influence of different charging structures on blasting vibration energy," Shock and Vibration, vol. 2015, Article ID 248739, 11 pages, 2015. 